\title{
La ganadería lanar en Madrid y su tierra durante la Edad Media
}

\author{
Tomás Puñal Fernández*
}

\begin{abstract}
RESUMEN ABSTRACT
El estudio de la ganadería en general y ovina en particular ofrece un campo muy generoso de investigación porque permite conocer muchas de las estructuras socioeconómicas regionales y locales de un país o territorio. En el caso de Madrid dicho estudio es importante por cuanto en el conjunto de las labores agropecuarias del concejo, las ganaderas fueron las que mejor marcaron su desarrollo económico. La tierra madrileña es tierra de ganado, sobre todo lanar, y ello fue el punto de referencia de diversas actividades económicas que iban desde el abastecimiento de carne para la alimentación hasta la obtención

de materia prima, lana y pieles, para las industrias textil y del cuero. Para tener una visión más amplia e interdisciplinar el presente estudio se ha hecho desde una doble perspectiva económica y social. Desde la ganadería estante y local a la

The study of the livestock in general and sheep in particular, offers a huge field to research as it allows to know many of the local and regional socioeconomic structures of a city or country. In the case of Madrid, that study is important because the sheep livestock is, among the rest of the agricultural activities, the main one for its contribution to the economic development. Madrid is a livestock area, mainly for sheep, as the point of refference of different economic activities, from the supply of meat for human feed to the obtention of raw materials, wool and leather for the textile and leather industries. In order to obtain a wider and interdisciplinar vision, this report has been made with both a social and economic approach. It comprises from the local and stable livestock to the migrating one, with an special mention to the Mesta and the quantitative aspects of the sheep
\end{abstract}

* UNED. 
trashumante, con especial mención a la Mesta y toda su problemática, asi como los aspectos cuantitativos derivados del número de ovejas y el tamaño y tipo de los rebaños y sus aspectos fiscales concomitantes. En relación a ello toda la infraestructura de pastos y cañadas. Los aspectos sociales se refieren a los propietarios de ovejas como una oligarquía rural de labradores enriquecidos, así como a los trabajadores del ganado, es decir los pastores, sus contratos, salarios $y$ condiciones de vida. En conjunto el panorama que se ofrece es muy significativo y permite acercarnos un poco más a la realidad socioeconómica del Madrid medieval. number, size and type of herds, fiscal consequences and the infrastructure of pastures and paths. The social aspects deal with the sheep owners as an enriched farm oligarchy, the shepherds work conditions, their labour contracts, their salaries and their way of life. The whole study is significant and allows us to know better the socioeconomic facts of Madrid in the middleages.

\section{INTRODUCCIÓN}

El desarrollo de la ganadería ovina fue siempre paralelo al de la agricultura desde los tiempos más antiguos. En la España prerromana la cría de ovejas debió ser importante en atención a los testimonios tanto documentales como arqueológicos conservados, que demuestran un gran desarrotlo de la cabaña ovina, la cual constituía la base de la economía de los pueblos celtíberos ${ }^{1}$. De esta manera en la Carpetania, en la que se incluía la región de Madrid, tenemos testimonios de una continuada tradición ovina en el seno de una economía pastoril que fue siempre intrínseca al espíritu del hombre castellano ${ }^{2}$.

Para la época medieval recogemos los primeros datos en el período musulmán en que se señala la existencia de una ganadería estacional entre los llanos de la campiña y la sierra, en el interior de las «kuras», que articulaban el territorio de Al-Andalus en la España omeya de los siglos VIII, IX y $\mathrm{X}^{3}$.

E. Laguna Sanz, Historia del Merino, Madrid, 1986, 36.

2 C. J. BISHKo, "El castellano hombre de llanura. La explotación ganadera en el área de frontera de La Mancha y Extremadura durante la Edad Media», Homenaje a J. Vicens Vives, BarceIona, 1965, 201-218.

3 C. J. BISHKO, «Sesenta años después. La Mesta de J. Klein a la luz de la investigación subsiguiente", en P. Garcia Martín y J. M. Sanchez Benito, (eds.), Contribución a la historia de la trashumancia en España, Madrid, 1986, 34. 
La tierra de Madrid, se incluía en la "kura" de Guadalajara ${ }^{4}$. Este territorio tanto por sus características geográficas como ambientales ofrecía las condiciones idóneas para la explotación ganadera en general, y ovina en particular, como indican los testimonios arqueológicos de la época ${ }^{5}$. Desde el siglo xII tenemos datos documentales para señalar esa presencia en la cría de ganado ovino, ovejas, carneros y corderos. Son los propios geógrafos musulmanes, como Al-Himyari (s. XII), los que señalan este hecho al referirse a las tierras cercanas a Madrid ${ }^{6}$.

Parece evidente que la llamada "reconquista" del Reino de Toledo desde 1085, y la creación de un espacio de frontera o extremadura en torno al valle del Tajo, no modificó demasiado las condiciones ganaderas preexistentes. Esto demuestra que el fenómeno de la conquista y repoblación de las tierras toledanas fue mas bien un hecho político que económico. En este caso determinadas estructuras económicas fueron respetadas y asimiladas, constituyéndose de esta forma una tradición histórica que se remonta a las épocas más remotas.

Constituidos los concejos de la Transierra (Toledo, Madrid, Talavera, etc.) ${ }^{7}$ durante el siglo XII, en un territorio de frontera, se siguió manteniendo una economía ganadera y pastoril importante como demuestran las referencias continuas a ganados ${ }^{8}$. Al mismo tiempo, junto a la existencia

4 Efectivamente la descripción más antigua que tenemos sobre el castillo de Madrid se debe al geógrafo musulmán Al-Razí en el siglo x. Según este autor el distrito de Guadalajara comprendía varios castilios fuertes y atalayas como los de Madrid, Castejón de Henares y Atienza, entre otros, E. Levi Provençal, La description de l'Espagne de Razí, París, 1936, 80 y ss. Otro autor como Alemany en su estudio señala que de la ciudad de Guadalajara, llamada Alfaraj o Aifar, dependian una serie de amelias o territorios como el del castillo de Madrid (Majrit o Mongerid), el de Uctrox (sin identificar), el de la Peña, el de Capatán (Sopetrán), el de Antixa (actual despoblado cerca de Guadalajara) y el de Alcalá (Alcalá de Henares); Alemany, “La geografía de la Península lbérica en los escritores árabes", Revista del centro de estudios históricos de Granada y su reino, $X, 1$ y 2 (1920).

5 Sobre arqueología madrileña tanto del periodo romano como del islámico, ver la serie de artículos publicados en el trabajo titulado, Madrid del siglo $1 \times$ al $x 1$, Madrid, Comunidad de Madrid, 1990, 205-303.

6 Al Himyari, Kitab Ar-Rawd Al-Mitar, trad. de M. P. Maestro Gonzalez, Valencia, 1963, 324.

Sobre la formación de los nuevos municipios y villas del antiguo territorio taifa de Toledo tras la conquista cristiana se puede consultar el trabajo de G. MARTiNEZ DiEZ, "Estructura administrativa local en el naciente Reino de Toledo", Estudios sobre Alfonso Vl y la reconquista de Toledo. Actas del II congreso internacional de estudios mozárabes, II, Toledo, 1988, 43-162.

8 En 1138 el arzobispo de Toledo don Raimundo con el consentimiento de los obispos de su provincia eclesiástica, dona al cabildo de canónigos de la catedral de Toledo la tercera parte de las recién constituidas rentas arzobispales de una serie de iglesias locales, entre las que se incluye Madrid. En el mismo documento se señalan los animales, el oro y la plata como bienes que debjan repartirse a medias entre el arzobispo y los canónigos. De ahí el valor que se daba al ganado; F. FiTA, «Madrid en el siglo XII", BRAH, VIII (1886), 51 y ss. 
de estos animales, aparecen menciones sobre el aprovechamiento de pastos y espacios para su cría ${ }^{9}$. Los mismos conflictos que surgen desde la época de Alfonso VII (1126-1157) sobre términos entre los concejos de Madrid y Segovia ${ }^{10}$, en un período todavía de formación y articulación territorial, lo demuestran. Por este mismo hecho Alfonso VIII en 1176 confirmaba a Madrid la posesión de pastos y montes dados por su abuelo el Emperador ${ }^{11}$. Las dificultades de la guerra, en un área de frontera como Madrid, no impidió el desarrollo de una ganadería ovina en una trashumancia interior, que en los meses de verano tenía como objetivo los pastos de la sierra de Guadarrama, y que en invierno avanzaría con cautela hacia las tierras llanas del sur ${ }^{12}$. En este sentido la confirmación del fuero de Uclés en 1179 por el maestre de Santiago, señala la existencia de una ganadería perfectamente organizada con movimientos estacionales fuera del término de Uclés, y de una ganadería foránea que acudía a sus montes ${ }^{13}$. Todo este panorama indica la existencia de una organización ganadera con mestas locales que aparecen documentadas desde el siglo XIII. Las de Alcaraz, Uclés y Madrid son tres de las más antiguas ${ }^{14}$. Los privilegios reales a favor de la ganadería, sobre todo a grandes propietarios (caballeros, monasterios, iglesias, etc.) ${ }^{15}$ señalan un interés por parte de las autoridades en que este sector de la economía prosperase.

La batalla de Las Navas de Tolosa en 1212 marcó un hito importante al crear una frontera estable, muy alejada de Madrid, que acabó con la situación de precariedad en que el territorio estuvo durante la decimosegunda centuria. La confirmación del fuero de Madrid por Alfonso VIII en $1202{ }^{16}$ in-

\footnotetext{
9 En este sentido las referencias a prados y montes para el ganado son frecuentes en la documentación madrileña del siglo Xil, (donaciones, compra-ventas). En 1197 Sancha Ordóñez, vecina de Carrantona en el término de Vallecas, daba a la orden militar de Santiago una heredad en el mismo lugar con : "Montibus et fontibus et pratis..."; F. FITA, "Madrid desde el año 1197 hasta el de 1202", BRAH, VIII (1886), 142 y ss.

10 Los documentos referentes a estos conflictos han sido publicados por T. DOMINGo PALACIO, Documentos del archivo general de la villa de Madrid, I, Madrid, 1888-1909.

11 J. González, El Reino de Castilla y Alfonso VIII, Madrid, 1960, docs. II, 242, 401 y ss.

12 R. PAStOR BAÑos, "La lana en Castilla y León antes de la organización de la Mesta", Contribución a la Historia de la Trashumancia..., 372.

13 El documento dice así: «Et ganado de alias terras qui in montes de Ucles steterint dent montadgo, medio ad senniore et medio ad concilio, si ibi voluerint homines de Ucles ambulare ad capere"; J. González, EI Reino de Castilla..., docs. II, 315, 517 y ss.

14 C. J. BISHKO, "Contribución a la Historia de la Trashumancia...", 51

15 En este sentido Alfonso $X$ concedió a los caballeros villanos de Madrid un privilegio de exención por la posesión de ganado. Así los que tuvieran entre cuatro y cien ovejas excusarian un vaquerizo, mientras que los que tuvieran cien o más excusarian un pastor; Memorial histórico español, I, 225. Así mismo el fuero de Uclés de 1179 determina el castigo para los hombres que dañasen el ganado de clérigos; J. GonzÁlez, El Reino de Castilla.... docs. II, 315, 318.
}

16 A. Gómez IGLESIAS, El fuero de Madrid, Madrid, 1963. 
dica una nueva realidad política que supone la consolidación de una comunidad de villa y tierra en un proceso de gestación largo -casi un siglo- repleto de avatares. La existencia de una ganadería ovina perfectamente reglamentada aparece a lo largo de las páginas del fuero. Señalaremos aquellas referencias más importantes:

1. Cap. XXII: «Quien Mesare»: El hombre de Madrid que mesare o hiriere o matare a un pastor o vaquerizo en una dehesa...

2. Cap. CILIO: Relación de los ejidos y abrevaderos de Madrid (bueyes y cuadrúpedos).

3. Cap. LVIII: "Quien permaneciera dentro de los ejidos de Madrid".

4. Cap. LXX: El prado de Atocha para el ganado de Madrid.

5. Cap. LXXIV: "Quien recibiere ganado sin orden de su dueño".

6. Cap. LXXVI: "Del que hallase ganado y no lo declarase al concejo de Madrid".

7. Cap. LXXXVI: «Quien ofreciere ganado a un alguacil (ovejas o corderos).

8. Cap. CXVII: Cualquier hombre de Madrid y su término no venda corderos a los carniceros para matar desde san Miguel hasta la Pascua Mayor.

Referencias a pastores y su protección (cap. XXII y LXXIV), así como a espacios propios y exclusivos para la ganadería (cap. CILIO, LVII y LXX), dehesas, prados y ejidos, demuestran una organización ganadera importante en general, y particularmente ovina, con menciones a ovejas y corderos (cap. LXXXV y CXVII). Resulta interesante el capítulo LXXVI sobre el hallazgo de ganado no declarado a las autoridades concejiles, lo que demuestra que a comienzos del siglo XIII, cuando Madrid era todavía zona de frontera, la práctica de capturar ganado como botín en razzias y cabalgadas, seguía estando vigente. También es importante la mención del ganado ovino como elemento de valor (cap. $L X X X V I$ ) a la hora de intentar comprar la voluntad de un oficial del concejo, así como la protección de estos animales, prohibiendo sacrificar corderos durante un período de tiempo (cap. CXVII), lo que hubiese supuesto un gran perjuicio para la cabaña ovina en atención a los recursos económicos que ofrecía.

El siglo XIII supone un fuerte avance en las estructuras ganaderas de los concejos castellanos y de la Transierra. Los litigios entre Madrid y Segovia por cuestión de términos, iniciados desde la segunda mitad del siglo XII, 
coritinuaron con mayor virulencia ${ }^{17}$. Es la prueba de que ambas ganaderías locales, la madrileña y la segoviana, se encontraban en un proceso de expansión, lo que les impelía a buscar más tierras en las proximidades serranas de lo que más tarde sería el Real de Manzanares ${ }^{18}$. Zona privilegiada, abundante en agua y pastizales, era el lugar idóneo para las actividades ganaderas. Independientemente, había razones estratégicas que animaron a los segovianos, con una economía fundamentalmente ganadera, a defender sus intereses en la zona por donde discurría un sector de la cañada real segoviana, atravesando tierras de Manzanares el Real y Collado Villalba ${ }^{19}$.

Es Fernando III quien había fallado favorablemente al concejo de Madrid en 1248 prohibiendo que los de Segovia hiciesen pueblas y colonizasen los términos de Manzanares el Real y Colmenar Viejo, considerados como propios de Madrid ${ }^{20}$. Los enfrentamientos entre ambos concejos determinaron que al año siguiente, en 1249, el monarca dispusiese que el lugar quedaba fuera del aprovechamiento de ambos, reservándose como zona forestal de explotación común. La sentencia prevalecería hasta que se fallase definitivamente sobre su jurisdicción ${ }^{21}$.

El problema lejos de resolverse continuó durante el siglo XIV. Madrid presenta en 1312 una información a Alfonso XI sobre sus derechos al Real de Manzanares ${ }^{22}$. Esta situación prevaleció hasta que el monarca entregó el Real a la reina doña Leonor ${ }^{23}$, pero siempre respetando los derechos de Madrid, que constantemente solicitaba del nuevo monarca reinante la oportuna confirmación de los mismos, con el fin de legalizar una situación que resultaba sumamente beneficiosa para el concejo, con una cabaña ganadera en aumento.

17 De este modo en 1239 Fernando III resuelve un litigio entre Madrid y Segovia por los térmirios de ambos concejos en el sector de Valdemoro; J. GonzÁlez, Reinado y diplomas de Fernando III, docs. III, 649, 183 y ss. Se puede consultar el trabajo de R. PASTOR BAÑos, "Apuntes para el estudio de los conflictos por el espacio ganadero del concejo de Madrid en el siglo xlli", I Jornadas de estudios sobre la provincia de Madrid, Madrid, 1980, 678-684.

18 E. TORMO, «El estrecho cerco del Madrid de la Edad Media por la admirable colonización Segoviana", BRAH, CXVIII (1946), 47-205.

19 M. Bellosillo, Castilla merinera. Las cañadas reales a través de su toponimia, Madrid, 1988,161 y ss.

20 J. Gonzalez, Reinado y diplomas..., docs. III, 767, 337.

24 J. Gonzalez, Reinado y diplomas..., docs. III, 784, 354.

22 T. DOMIngo Palacio, 1, 213 y ss

23 T. DOMINGo Palacio, I, 223. 


\section{LA GANADERIIA ESTANTE}

Desde mediados del siglo $x v$ y hasta comienzos del siglo $x \mathrm{~V}$, la ganadería estante experimentó un fuerte crecimiento, lo que no impidió un predominio numérico de los trashumantes ${ }^{24}$. Este desarrollo pudo deberse a varios factores. En primer lugar el auge de una ganadería comercial, básicamente ovina, en unas estructuras de mercado a las que los pequeños y medianos propietarios de ovejas deseaban acceder como medio de superar la crisis económica bajomedieval. Como sucedió con los monocultivos (vid y cereal) y cultivos especializados (plantas textiles, tintóreas, etc.), el comercio y la industria de la lana suponía una importante fuente de ingresos para los propietarios de rebaños, tanto campesinos como no. El binomio agricultura-ganadería se resolvió con la aparición de cultivos asociados a la ganadería estante, cereales y vid ${ }^{25}$, así como con la creación de nuevos espacios de pastizal, que en muchos casos supuso un importante obstáculo a la agricultura ${ }^{26}$.

Escasos han sido los trabajos sobre ganadería estante castellana ${ }^{27}$. Resulta evidente que éste ofrece muchas más dificultades que el de los grandes rebaños de la Mesta, debido, casi siempre, a una documentación escasa y fragmentaria. Sin embargo aunque se trate de una ganadería falta de gravámenes fiscales, el estudio de la misma ofrece otras posibilidades, no menos ventajosas, en relación a una aproximación numérica de su volumen para un lugar y en un período determinados.

Las infracciones cometidas por los animales sobre los cultivos, en ese siempre difícil equilibrio entre actividades agrarias y ganaderas, constituyen nuestra mejor fuente de información. La determinación de caloñas a satisfacer a los propietarios y renteros de las tierras afectadas por la intromisión de ganado ovino, reflejan, casi siempre, aunque de forma un tanto genérica, el número de ovejas causantes del daño. Sin embargo debemos considerar que ni todas las ovejas cometían infracciones, ni en la

24 F. Ruiz Martin, "Pastos y ganaderos en Castilla. La Mesta (1450-1600)", en Contribución a la historia de la trashumancia... 274.

25 E. Cantera Montenegro, La Agricultura en la Edad Media, "Cuadernos de Historia", 36, Madrid, 1997.

${ }_{26} \mathrm{P}$. Iradiel en su estudio sobre la industria textil en Cuenca ha señalado que el aumento de los rebaños puso en peligro desde la crisis del siglo XIV la agricultura y el mismo aprovisionamiento de cereales a la ciudad; P. IRADIEL, Evolución de la industria textil castellana en los siglos XIII al XVI, Salamanca, 1974, 60 .

${ }_{27}$ Ver como ejemplo el cálculo del porcentaje de ganado ovino que hace M. Martínez basándose en las caloñas de los ganados hallados en la huerta murciana; M. MARTinEZ, La Industria del vestido en Murcia (ss. XII-xV), Murcia, 1988, 21 y ss. 
documentación aparece todo el ganado ovino, con lo que los datos obtenidos resultan fiables pero relativos, y mas que nada representativos de una realidad que estimamos siempre mucho mayor de lo que reflejan las cifras que se puedan exponer. Para Madrid disponemos de una abundante información sobre ovejas. Su regular aparición en la documentación puede deberse a dos factores. Primero a lo que hemos considerado un importante aumento de la cabaña ovina, según la evolución ya expuesta en el epígrafe anterior. La presencia de estos animales a lo largo de todo el año en un concejo de reducidas dimensiones, limitado en su expansión por Toledo y Segovia, determinó un difícil equilibrio entre las tierras de sembradura y los espacios destinados a los animales de labor, junto a los dedicados exciusivamente al pasto de la ganadería ovina, caprina y porcina. La ampliación de los mismos hubiese determinado restar espacio, tanto a la producción de cereales y vino ${ }^{28}$ destinada al abastecimiento y el comercio, como a la misma supervivencia de la cabaña de bóvidos y equinos. En todo caso, se intentó hallar una solución intermedia entre el aprovechamiento de los barbechos y de aquellas tierras de cultivo, segadas o vendimiadas, donde por un determinado período de tiempo las autoridades permitían la entrada de ganado, y cuyos excrementos resultaban beneficiosos para la tierra. En segundo lugar, debemos considerar que el ganado estante tenía cierta facilidad de movimiento en espacios de corto radio de acción. Estos desplazamientos se efectuaban, a menudo, entre varios distritos municipales mancomunados a efectos de pastos ${ }^{29}$. Son los ganados llamados riberiegos, algunos de los cuales eran objeto de compraventa para las carnicerías, por lo que también recibian el nombre de merchanegos ${ }^{30}$.

En Madrid hubo un importante desarrollo de la ganadería estante. De este modo se nos informa de los daños ocasionados por el ganado ovino tanto en los meses de primavera y verano, coincidentes con la estancia en tierras madrileñas de los trashumantes durante la veranada,

${ }_{28}$ Hemos intentado calcular este espacio en nuestro trabajo sobre el vino en Madrid donde ofrecemos un cuadro en el que se refleja la distribución en metros cuadrados de la superficie del viñedo en algunas zonas del concejo; T. PUÑAL FERNÁNDEZ, “La producción y el comercio de vino en el Madrid Medieval», En La España Medieval, 17 (1994), 185-212, 195.

29 Un ejemplo lo tenemos en 1452 en que dos vecinos de la tierra de Madrid unen sus rebaños de ovejas para llevarlos a herbajear al término de Paracuellos, perteneciente a la orden militar de Santiago. En efecto Alonso, hermano de Juan Crespo, vecino de Madrid, mete sesenta ovejas con el ganado de Esteban Sánchez, vecino de Rejas, para llevar!o conjuntamente a pastar a tierra de Paracuellos, en las riberas del Jarama; Archivo de la Villa de Madrid (en adelante AV). MinUTAS... II, f. 249 r-v.

30 Ruiz Martín, 274. 
como durante el otoño y los meses invernales, en que sólo quedaban los modestos rebaños que no participaban en la trashumancia. Ofrecemos a modo de ejemplo una relación de los mismos, indicando años, número de ovejas que han producido el daño, así como el tiempo y lugar del mismo.

La cabaña ovina estante en Madrid

\begin{tabular}{cccc}
\hline AÑOS & MESES & OVEJAS & LUGAR \\
\hline 1442 & noviembre-febrero & 150 & Prado de Carabanchel \\
1442 & marzo & 140 & Trigos \\
1444 & marzo & 300 & Avena \\
1444 & octubre-abril & 500 & Dehesa de Zorita \\
1460 & septiembre-febrero & 500 & Soto de Perales \\
1460 & enero-febrero & 300 & Prado de Caraza \\
1460 & febrero & 200 & Cebada \\
1463 & enero-junio & 300 & Prado de Torrejón \\
1472 & octubre-febrero & 200 & Vinas \\
1472 & diciembre-marzo & 400 & Prado de Meaques \\
1472 & enero-marzo & 300 & Prado de Meaques \\
1472 & febrero & 150 & Majuelo \\
\hline
\end{tabular}

La presencia de ovejas constituyó una especie de trashumancia local que se realizaba a través de una tupida red de caminos rurales, que además de las cañadas podian ser carriles, sendas $y$ veredas ${ }^{31}$, que transcurrian entre mieses y viñas. Hemos estudiado en su momento la relación de estos caminos en los cuatro sesmos que conformaban la tierra madrileña: Madrid, Aravaca, Vallecas y Villaverde ${ }^{32}$. Señalaremos aquellos topónimos que hacen referencia al entorno más o menos próximo de los caminos ${ }^{33}$.

31 T. Puñal Fernandez, "Los caminos ruraies del concejo de Madrid en la Edad Media", Actas del l congreso internacional sobre camineria hispánica, Madrid, 1993, 217-237.

32 R. GIBERT, El concejo de Madrid, su organización en los siglos XII-XV, Madrid, 1949.

33 Bellosillo, 20 y ss. 
SESMO DE MADRID:

- Vereda del Lobo que va de Madrid a Las Palomeras.

- Camino que va de Madrid a Prado Lombardos.

SESMO DE ARAVACA:

- Camino de la Dehesa de Boadilla con el arroyo de Cadozo.

- Camino de Boadilla al Soto.

- Camino de La Lobera en Boadilla.

- Camino del Monte a Leganés.

- Camino de Leganés a Los Prados.

- Camino de La Pasadilla a la Dehesa de Palacio en Carabanchel.

- Camino del Monte en Carabanchel.

- Vereda de la Dehesilla de Montiel a las Navas de la Dehesa en Carabanchel.

SESMO DE VALLECAS:

- Carril de Barajas al Monte en Hortaleza.

- Camino que va a la vega de Biveros.

- Camino que va de Biveros a los Sotos de Varalcalde.

- Camino que va de Biveros al Sotillo.

- Senda Galiana, cerca del camino de Alcalá.

- Camino que va a Paracuellos cerca de la Senda Galiana y el ejido de Biveros.

- Carnino de san Cristóbal en Vicálvaro que va a dar a la dehesa de Rejas.

SESMO DE VILLAVERDE:

- Camino de Villaverde a la pradera de los Llanos de Arriba.

Como se puede ver en la toponimia aparecen referencias a ejidos, prados, praderas, dehesas, sotos y montes, todos lugares de pasto y abrevadero para el ganado. En cuanto a la tipología se citan desde cañadas, pasando por caminos, veredas, carriles y sendas.

En cuanto a las cañadas locales tenemos la relación de aquéllas que recorrían los términos de los respectivos lugares, y que servían de base a la cabaña ovina autóctona. Para su reconstrucción y trazado hemos utilizado la toponimia que nos ofrecían distinto tipos de fuentes, desde apeos de tierras hasta la cartografía histórica del término de Madrid ${ }^{34}$. Son las siguientes:

34 Datos tomados del Instituto Geográfico del Ejército, hoja mariamétrica, $n^{2} 145$, escala $1 / 2000$. 


\section{Cañadas madrileñas}

\section{SESMO DE ARAVACA}

- CARABANCHELES:

- Cañada de Prado Longo, entre el camino de Toledo y el de Villaverde.

- Los Merinos, topónimo junto al camino de Leganés a Madrid.

SESMO DE VALLECAS

- VALLECAS:

- Cañada Real de las Merinas: Esta cañada, la más importante, conocida como ramal conquense, entraba en Madrid por el puente de Biveros, recorriendo los términos de Coslada y Ribas. Seguia en su trazado el margen izquierdo del valle del Jarama. Abandonaba el término de Ribas por Valdemingómez entrando en territorio vallecano por el sector sureste. Atravesaba la cañada del Congosto y los prados de Salmedina y la Torrecilla, para cruzar el Manzanares y entrar en el término de Getafe. De aqui se dirigía hacia Pinto por donde abandonaba la jurisdicción madrileña, cruzando de nuevo el Jarama por el puente de Villanueva en dirección a Chinchón y el paso de Fuentidueña de Tajo.

- Cañada que va hacia Vallecas en linde de los ejidos de Madrid.

- Cañada del Congosto: Es de las cañadas locales, una de las más grandes. Salía de Vallecas y atravesaba la Cañada Real continuando hacia el sur.

- Cañada del Santísimo: Iba desde el camino de las Canteras y atravesaba la cañada del Congosto.

- CANILLAS:

- Cañada cerca del camino de Canillas a Madrid.

- Cañada en el valle de la Fuente del Pozuelo.

- CANILLEJAS:

- Cañada que llega al camino que va de Canillejas a Madrid.

- hoRTALEZA:

- Camino de los Cenagales o Cañadas: Iba desde Hortaleza paralelo al camino viejo de Burgos.

\section{SESMO DE VILLAVERDE}

- VILLAVERDE:

- Cañada que sale de la aldea y va a parar al camino de Toledo.

- Cañada que sale de la aldea y va hasta el camino de Perales.

La información que tenemos sobre la ganadería estante resulta ser la más certera e importante tanto a nivel cualitativo - relación de propietarios 
de ovejas, procedencia de las mismas, etc. - como cuantitativo - número de cabezas- Sin embargo no es la única. Contratos de compra-venta de ganado, de aparcería en el arrendamiento de ovejas, o de pastoría, nos permiten calcular su volumen ${ }^{35}$. Estas transacciones se solían realizar en ferias y mercados ${ }^{36}$. Frente a la indeterminación, algunos contratos son más específicos no sólo en cuanto al número, sino también en lo referente al tipo. Así los treinta carneros que en 1453 un vecino de Alcorcón vendía a otro de Leganés ${ }^{37}$. Es frecuente que en ocasiones se detalle el sexo y la edad. De esta manera en 1471 un vecino de Villaverde vendía a Juan González Donayre, vecino de Getafe, cuatro corderos machos de la nacencia de ese año ${ }^{38}$, y en 1472 un vecino de Madrid demandaba a su vendedor la entrega de una oveja de dos dientes, fórmula empleada para determinar la edad del ganado ${ }^{39}$.

Venta de ganado ovino en Madrid

\begin{tabular}{|c|c|c|c|}
\hline AÑO & VENDEDOR & COMPRADOR & TIPOS \\
\hline 1449 & $\begin{array}{l}\text { Fraym Aben Xuxe } \\
\text { vecino de Madrid }\end{array}$ & $\begin{array}{l}\text { D. López Guadalajara } \\
\text { vecino de Madrid }\end{array}$ & ovejas \\
\hline 1449 & $\begin{array}{l}\text { Pedro González } \\
\text { vecino de Fregacedos }\end{array}$ & $\begin{array}{l}\text { Alonso Rodríguez } \\
\text { vecino de Madrid }\end{array}$ & ovejas \\
\hline 1453 & $\begin{array}{l}\text { Pedro de Manzanares } \\
\text { vecino de Alcorcón }\end{array}$ & $\begin{array}{l}\text { Gonzalo Rodríguez } \\
\text { vecino de Leganés }\end{array}$ & carneros \\
\hline 1471 & $\begin{array}{l}\text { Miguel de Overa } \\
\text { vecino de Getafe }\end{array}$ & $\begin{array}{l}\text { Diego Donayre } \\
\text { vecino de Getafe }\end{array}$ & ovejas \\
\hline 1471 & $\begin{array}{l}\text { Maestro Hazán } \\
\text { vecino de Madrid }\end{array}$ & $\begin{array}{l}\text { Diego Navarro } \\
\text { vecino de Madrid }\end{array}$ & corderos \\
\hline 1471 & $\begin{array}{l}\text { Domingo Fernández } \\
\text { vecino de Villaverde }\end{array}$ & $\begin{array}{l}\text { J. González Donayre } \\
\text { vecino de Getafe }\end{array}$ & corderos \\
\hline 1471 & $\begin{array}{l}\text { Abraham Çidre } \\
\text { vecino de Madrid }\end{array}$ & $\begin{array}{l}\text { Abdaliá Toledano } \\
\text { vecino de Madrid }\end{array}$ & corderos \\
\hline 1471 & $\begin{array}{l}\text { Juan de Toledo } \\
\text { vecino de Madrid }\end{array}$ & $\begin{array}{l}\text { Maria García } \\
\text { vecina de Getafe }\end{array}$ & ovejas \\
\hline 1471 & $\begin{array}{l}\text { Alonso de Santos } \\
\text { vecino de Madrid }\end{array}$ & $\begin{array}{l}\text { Juan García } \\
\text { vecino de Fuencarral }\end{array}$ & ovejas \\
\hline 1471 & $\begin{array}{l}\text { Fernando Díaz } \\
\text { vecino de Madrid }\end{array}$ & $\begin{array}{l}\text { P. Sánchez Mellado } \\
\text { vecino de Vallecas }\end{array}$ & ovejas \\
\hline 1472 & $\begin{array}{l}\text { Fdo. de San Pedro } \\
\text { vecino de Madrid }\end{array}$ & $\begin{array}{l}\text { Abraham Çidre } \\
\text { vecino de Madrid }\end{array}$ & ovejas \\
\hline
\end{tabular}

AV, MINUTAS... II, f. 42r.

AV, MINUTAS... II, f. $64 \mathrm{v}$.

AV, MINUTAS..., II, f. 326v-327r.

AV, MINUTAS..., III, f. 339r.

39 AV, MINUTAS..., III, f. $441 \mathrm{v}$. 
Junto a este tipo de contratos, inventarios de bienes y tutorías, ofrecen el resto de la información. Sobre tutorías de menores, muy frecuentes en la documentación madrileña del siglo $x \mathrm{v}^{40}$, tenemos algunos casos en los que se describen los bienes muebles y raíces del finado a administrar por un tutor o tutores, casi siempre familiares directos, y por lo general con el consentimiento del concejo. Tenemos ejemplos en los que se señala este hecho. Algunos de ellos se refieren al arrendamiento de ovejas en contratos de aparcería por los tutores de los menores en cuestión ${ }^{41}$, otros reflejan simplemente la relación de ganado de los menores ${ }^{42}$.

A continuación ofrecemos un cuadro en el que se indican el año, el número de ovejas y su procedencia. De esta manera obtendremos, grosso modo, el volumen de la cabaña ovina en Madrid. Haremos una distinción entre la época de Juan II y la de Enrique IV, calculando el número de ovejas en cada reinado. Al final daremos una cifra que globalice el período que estudiamos, debiendo tener siempre en cuenta la relatividad de la misma.

\section{La cabaña ovina en Madrid} Juan /I (1406-1454)

\begin{tabular}{ccl}
\hline AÑO & OVEJAS & PROCEDENCIA \\
\hline 1442 & 150 & Carabanchel Alto \\
1442 & 140 & Getafe \\
1444 & 300 & Fuencarral \\
1444 & 500 & Zorita \\
1444 & 100 & Vallecas \\
1444 & 150 & Alcorcón \\
1444 & 30 & Hortaleza \\
\hline
\end{tabular}

40 En este caso pensamos que los turbulentos reinados de Juan II y Enrique IV, plagados de enfrentamientos y guerras civiles y externas, determinaron frecuentemente una acusada mortandad entre la población pechera que estaba obligada a participar en estas expediciones. Otros factores como epidemias y hambres, también frecuentes en el período, debieron influir.

4) Es el caso de Nicolás Garcia y Benito Sánchez, hijos de Pedro Fernández, tutores de sus sobrinos, hijos de Andrés Fernández, vecinos de Carabanchel Bajo, que en enero de 1449 arriendan en su nombre a Juan Alonso, vecino del lugar, seis ovejas fresqueyguardas; una de dos dientes, y otra de cuatro, junto a una borrega y un borrego de la nacencia de ese año; AV, MINUTAS..., II, f. $6 r$.

En febrero del mismo año Pedro Sánchez Sacristán, tutor de sus sobrinos, hijos de Juan Martín Eleno, vecino de Getafe, arrienda a Antón Sánchez, vecino del lugar, ocho ovejas de dos y cuatro dientes; AV, MINUTAS..., II, f. $16 \mathrm{r}$.

42 En este caso los tutores son Juan Alonso y Pedro Gómez, hijos de doña Teresa, que actúan en representación de Isabel, María y Juana, hijas de Alonso García, su hermano difunto, vecino de Carabanchel Bajo; AV, MINUTAS... II, f. 39r-v. 


\begin{tabular}{ccl}
\hline & $\begin{array}{c}\text { La cabaña ovina en Madrid } \\
\text { Juan II (1406-1454) }\end{array}$ \\
& OVEJAS & PROCEDEnuación) \\
\hline AÑNO & 30 & Carabanchel Bajo \\
\hline 1444 & 300 & Carabanchel Bajo \\
1444 & 200 & Aravaca \\
1444 & 300 & Carabanchel Alto \\
1444 & 300 & Madrid \\
1445 & 100 & Carabanchel Bajo \\
1445 & 15 & Villaverde \\
1445 & 200 & Calatrava \\
1445 & 300 & Meaque de Arriba \\
1449 & 300 & Alcorcón \\
1449 & $0 v e j a s$ & Vallecas \\
1449 & 15 & Villaverde \\
1449 & 60 & Rejas \\
1449 & 600 & Villaverde \\
1449 & 500 & Getafe \\
1449 & 350 & Caraque de Arriba \\
1449 & 600 & Acedinas \\
1449 & 500 & Villaverde \\
1452 & 150 & Zorita \\
1452 & 100 & \\
1452 & & \\
\hline
\end{tabular}

TOTAL: 6.290 ovejas.

\section{La cabaña ovina en Madrid}

Enrique IV (1454-1474)

\begin{tabular}{ccl}
\hline AÑO & OVEJAS & PROCEDENCIA \\
\hline 1460 & 500 & Perales \\
1460 & 300 & Caraza \\
1460 & 200 & Leganés \\
1460 & 300 & Butarque \\
1462 & ovejas & Leganés \\
1463 & 300 & Loranca \\
1463 & 300 & Aravaca \\
1463 & 100 & Madrid \\
1463 & 200 & Butarque \\
1464 & 100 & Aravaca \\
1464 & 200 & Aravaca \\
1464 & 300 & Getafe \\
1466 & 200 & Overa \\
1466 & 450 & Acedinas \\
1466 & 440 & Acedinas \\
1466 & 300 & La Serrezuela
\end{tabular}


La cabaña ovina en Madrid

Enrique IV (1454-1474) (continuación)

\begin{tabular}{|c|c|c|}
\hline AÑO & OVEJAS & PROCEDENCIA \\
\hline 1471 & 400 & Fuencarral \\
\hline 1471 & 150 & Hortaleza \\
\hline 1471 & 200 & Getafe \\
\hline 1471 & 200 & Butarque \\
\hline 1471 & 60 & - \\
\hline 1471 & 150 & Getafe \\
\hline $147 \uparrow$ & 200 & Hortaleza \\
\hline 1471 & 350 & Alcorcón \\
\hline 1472 & 200 & Getafe \\
\hline 1472 & 200 & Getafe \\
\hline 1472 & 400 & Meaques \\
\hline 1472 & 400 & Carabanchel Alto \\
\hline 1472 & 150 & Getafe \\
\hline 1472 & 400 & La Zarzuela \\
\hline 1472 & 200 & Alarnes \\
\hline 1472 & 50 & Getafe \\
\hline 1472 & 600 & Madrid \\
\hline 1472 & 400 & Madrid \\
\hline 1472 & 600 & Getafe \\
\hline 1472 & 400 & Getafe \\
\hline 1472 & 200 & Hormera \\
\hline 1472 & 300 & - \\
\hline 1472 & ovejas & - \\
\hline 1472 & 500 & Leganés \\
\hline 1472 & 200 & Vicálvaro \\
\hline 1472 & 250 & - \\
\hline 1472 & 200 & - \\
\hline 1473 & 150 & Fregacedos \\
\hline 1473 & 300 & Acedinas \\
\hline 1473 & ovejas & Carabanchel Alto \\
\hline 1473 & 300 & Boadilla \\
\hline 1473 & 400 & Villaverde \\
\hline 1473 & 500 & Madrid \\
\hline 1473 & 400 & Aluche \\
\hline 1474 & 400 & Alcorcón \\
\hline
\end{tabular}

TOTAL: 14.000 ovejas.

TOTAL NÚMERO DE OVEJAS DEL PERÍODO: 20.290 ovejas.

En el análisis del cuadro anterior observamos en primer lugar unas cifras muy desiguales en lo que respecta al número de ovejas. Así las seiscientas cabezas representan el índice más alto, correspondiéndose tanto a 
la época de Juan II ${ }^{43}$, como a la de Enrique IV ${ }^{44}$. Por el contrario el índice más bajo son las tan sólo quince ovejas que aparecen en $1445{ }^{45}$. Para la etapa enriqueña, y más concretamente para el año 1472 , el modesto rebaño de Catalina Alonso, vecina de Getafe, formado por cincuenta ovejas, constituye el exponente más bajo ${ }^{46}$.

En todo caso el porcentaje medio de estos rebaños se sitúa en un nivel que no supera las seiscientas cabezas y que no resulta inferior a las treinta, exceptuando los casos citados de quince ovejas. De esta forma podemos establecer unos niveles, siguiendo criterios cuantitativos en los que se expresa la siguiente jerarquía:

1. Pequeños Rebaños: Entre 15-100 ovejas.

2. Rebaños Modestos: Entre 100-600 ovejas.

3. Grandes Rebaños: Más de 600 ovejas.

Porcentaje medio del tamaño de los rebaños

\begin{tabular}{ccc}
\hline NÚMERO DE OVEJAS & NÚMERO DE REBAÑOS & PORCENTAJE \\
\hline 15 & 2 & 1,5 \\
$16-30$ & 2 & 1,5 \\
$31-60$ & 3 & 2,2 \\
$61-100$ & 5 & 3,8 \\
$101-200$ & 22 & 16,7 \\
$201-300$ & 16 & 12,1 \\
$301-400$ & 11 & 3,3 \\
$401-500$ & 8 & 6,0 \\
$501-600$ & 4 & 3,0 \\
\hline
\end{tabular}

43 Son los casos de García Fernández, pastor, cuyas seiscientas ovejas en 1449 habían entrado en un trigo sembrado en el lugar conocido como La Tova, en el término de Rejas; AV, MINUTAS... II, f. 122v. También es el caso de Andrés García de Hurosa, vecino de Madrid, pastor de Juan Alonso, cuyas seiscientas reses habian penetrado en 1449 en los prados de Caraque de Arriba; AV, MINUTAS... II, f. 183v.

44 Así las seiscientas ovejas de Alonso Martínez Pingarrón, vecino de Getafe, que habían entrado en el prado vedado de Allende, en el término del lugar; AV, MINUTAS... III, f. 482r.; 0 las seiscientas reses de Maestro Abdallá Toledano, moro, vecino de Madrid, que lo habian hecho en los Prados Gobaldo y Serrano, en el término de la villa, en 1472; AV, MINUTAS... III, f. $458 \mathrm{v}$.

45 Es el caso de Benito Sánchez cuyo ganado había hecho daño en unas viñas en Valdemedio, en el término de Carabanchel Bajo; AV, MINUTAS... I, f. 281 v. En 1449 son las quince ovejas de Alonso García las que habian entrado en una viña con fruto en el lugar de Carrantona, término de Vallecas; AV, MINUTAS... II, f. 106r.

46 En el documento se señala que las mismas habían entrado en la dehesa del Yuncar en Getafe, por lo que se pedian las caloñas correspondientes; AV, MINUTAS... III, f. 453v. 
Los porcentajes revelan la existencia de unos rebaños de tipo medio, siendo los más frecuentes aquellos compuestos por entre cien y doscientas ovejas. Le siguen todavía rebaños modestos de entre doscientas, trescientas y cuatrocientas reses.

Menos frecuentes que los anteriores son los hatos de cuatrocientas y quinientas cabezas, tan sólo ocho rebaños, reduciéndose a la mitad la cifra de aquellos que llegan o se aproximan a las seiscientas. Los rebaños pequeños de entre quince y cien ovejas son también poco numerosos.

En un análisis por años y décadas observamos, así mismo, un predominio de los rebaños de tipo medio. Sucede por ejemplo, en la década de los años cuarenta $(1442,1444,1445$ y 1449), y en la de los cincuenta (1452). En las dos décadas restantes hasta finalizar el período, sucede lo mismo tanto en los años sesenta $(1460,1463,1464$ y 1466), como en los setenta (1471, 1472, 1473 y 1474).

Esta misma disposición se halla en un estudio por reinados. Sin embargo conviene señalar que la información referente al número de ovejas y rebaños es mucho más abundante para la época de Enrique IV, aproximadamente el doble con respecto al reinado anterior. En principio se pudiera pensar que ello se debe a que en la documentación prácticamente se han conservado los años correlativos de Enrique IV, mientras que para Juan II las noticias que ofrecen las fuentes comienzan más tarde, y además con importantes lagunas. Tenemos, pues, que nos falta casi la mitad de información, teniendo en cuenta que este monarca comienza su reinado en 1406. Sin embargo parece constatarse un aumento del número de ovejas en el período enriqueño.

En resumen podemos señalar que la cabaña ovina madrileña se caracterizó por rebaños modestos de entre cien y seiscientas ovejas, representando un porcentaje bajo los rebaños pequeños o los muy grandes. Este dato nos indica que en Madrid prevaleció una ganadería estante de tipo medio, acorde con las propias capacidades físicas y geográficas de un concejo de mediana extensión, y bastante representativa, a nuestro modo de ver, de la realidad ganadera de las villas y pequeños municipios castellanos del siglo xV.

\section{LA GANADERÍA TRASHUMANTE: LA MESTA MADRILEÑA}

La trashumancia experimentó un fuerte desarrollo, concretamente durante el periodo que estudiamos, según se deduce de los aspectos fiscales relacionados con el trasiego de ovejas ${ }^{47}$.

47 Estos aspectos han sido analizados por M. A. LADERO QUESADA, La hacienda real de Castilla en el siglo xv, La Laguna, 1973. 
Es evidente que algunos rebaños madrileños participaban en los circuitos trashumantes, lo que nos permite hablar de la existencia de una mesta local que aparece documentada desde el siglo xIII. La misma estaba compuesta por los rebaños de los pequeños y medianos propietarios, junto a los de la oligarquía urbana e instituciones eclesiásticas. Monasterios como el de santo Domingo el Real con más de mil cabezas de ganado ${ }^{48}$, o el de san Jerónimo ${ }^{49}$, constituyen un buen exponente.

La Mesta madrileña se organizó en un circuito norte-sur que a comienzos del otoño, aproximadamente a finales de octubre y durante el mes de noviembre, iniciaba la marcha de los rebaños hacia los territorios de La Mancha y norte de Andalucia ${ }^{50}$. Este hecho aparece demostrado por las numerosas noticias que recogemos en la documentación referentes a los daños ocasionados por las ovejas en los meses de octubre y noviembre, coincidiendo con las labores de la vendimia ${ }^{51}$. Aquí permanecian durante todo el invierno, para iniciar el regreso a comienzos de la primavera. A finales de marzo o principios de abril ${ }^{52}$ los ganados ya habian llegado a Madrid para iniciar a partir de este momento la veranada. Precisamente los casos de perjuicios realizados por los rebaños en prados y tierras de sembradura son muy abundantes durante los meses de

48 J. R. Romero Fernández-Pacheco, "Madrid y la Mesta en la Edad Media», Caminos y caminantes por las tierras del Madrid Medieval, LAYA, 12, Madrid, 1994, 107-115, 109.

49 En 1464 Enrique IV concede a este monasterio por él fundado doscientos carneros anuales. El privilegio está fechado en Valladolid el 10 de diciembre de 1464; AGS., Privilegios Reales, 58-61.

50 Concretamente en las tierras del norte de Jaén, en el valle de Alcudia, al norte de Córdoba, o en las Ilanuras manchegas de Ciudad Real y Albacete pertenecientes a las órdenes militares; ROMERO, "Madrid y la Mesta...", 110.

51 De esta manera recogemos información desde el año 1442 hasta 1472. En el primero de los años Pedro Ruiz de Alarnes, vecino de Getafe, demandaba caloñas a Pedro Sánchez, vecino del lugar, por las doscientas ovejas que habían entrado en una viña suya estando labrada y con fruto durante el mes de octubre; AV, MINUTAS... I, f. 62v.

En 1445 Alvar López, vecino de Madrid, ponía idéntica demanda a Gonzalo Ruiz por las cien ovejas que habian entrado en un majuelo labrado y ya sin fruto en el mes de octubre; AV, MINUTAS... 1, f. 280r.

Durante el mes de noviembre aparecen también algunos casos como el de Catalina González, vecina de Carabanchel Bajo y las cuatrocientas ovejas que entran en una cebada suya en este mes, en 1472; o el caso de Alonso Calvo, vecino del lugar, y las doscientas reses que hacen daño en un trigo que tenía sembrado y nacido en el lugar del Algasorro, también durante el mes de noviembre; AV, MINUTAS... III, f. 434r y 562 r.

52 Pondremos dos ejemplos ilustrativos. En 1449 Gonzalo García acusaba a Pedro Martín, pastor, vecino de Carabanchel Alto, de que sus trescientas ovejas habían entrado en los prados vedados de Meaque de Arriba en el mes de abril; AV, MINUTAS... II, t. 100r.

En 1463 Benito Sánchez Claros ponía idéntica demanda a un vecino de Carabanchel Alto por las doscientas ovejas que en el mes de marzo habían causado daño en su majuelo de Valdebutarque; AV, MINUTAS..., III, f. $45 \mathrm{r}$. 
verano, tanto en panes aún no segados como en vides a punto de ser vendimiadas ${ }^{53}$.

Los propietarios de ovejas y sus pastores se reunian en la villa tres veces al año para hacer mesta. Esta reuniones coincidían con el calendario litúrgico, que a su vez estaba en relación con el agrario. Los pastores acudían entonces a los corrales o apartaderos de ganado situados cerca de la ermita de san Millán, junto al camino de Toledo. La primera concentración se realizaba en febrero, coincidiendo con la fiesta de santa María Candelaria y la llegada de los rebaños a Madrid, después de la invernada. La segunda el 24 de junio, día de san Juan, al ínicio de la estación de verano, y la última el día de san Miguel, 29 de septiembre, cuando el ganado se preparaba para iniciar de nuevo la marcha hacia el sur, a comienzos del otoño ${ }^{54}$. En esta mesta de fines de septiembre se debía satisfacer el servicio y montazgo.

Junto con las mestas celebradas en la villa, algunos autores han señalado la existencia de reuniones locales en diversos puntos de la tierra y señoríos comarcanos. Tal es el caso de Pinto, Barajas, Leganés, Fuencarral, Alcobendas, Chamartín, Vallecas, Getafe, Móstoles, Hortaleza y San Sebastián de los Reyes ${ }^{55}$.

\section{LA GANADERIÁA FORÁNEA}

La situación geográfica de Madrid como cruce de caminos determinó la existencia también de una ganadería ovina que cruzaba parte de su territorio en su marcha hacia los "extremos". Sin embargo las autoridades madrileñas iniciaron desde el siglo XIV una dura batalla por impedir dos cosas. Primero que por la tierra de Madrid pasasen cañadas, y segundo que los alcaldes de la Mesta y sus subalternos tuviesen capacidad de juicio en los debates que se pudiesen plantear entre los pastores y propietarios de los rebaños foráneos y el concejo de Madrid. Para ello no dudaron en acudir a los sucesivos monarcas reinantes, pues sólo el rey bajo cuya protección estaba la Mesta, podía determinar tal situación para Madrid, que además era concejo de realengo.

\footnotetext{
53 Precisamente en el mes de octubre de 1464 el alcalde condenaba a Juan de Alcalá a pagar la cuarta parte de lo que había cobrado a unos pastores de ganado extremeño que habia hallado paciendo en ciertas viñas; AV, MINUTAS... III, 1 . $168 \mathrm{r}$.

54 ROMERO, "Madrid y la Mesta...", 111.

55 F. COS GAYón, "La Mesta», en Contribución a la historia de la trashumancia..., 228.
} 
Las primeras referencias sobre este asunto son de principios del siglo XIV, reinando Fernando IV. El monarca había fallado favorablemente al concejo madrileño a través de dos cartas, fechadas en Toledo el año 1303. Una representación concejil formada por el alguacil y algunos caballeros se había dirigido al rey protestando por el paso de ganado foráneo, tanto por la villa como por el término de Madrid. Este hecho venía dado porque los pastores no querían utilizar la cañada real que discurría por tierras del Real de Manzanares, desviándose hacia Madrid ${ }^{56}$, a través de una serie de ramales que venían hacia Colmenar Viejo para llegar hasta la misma villa. La utilización regular de este ramal de la cañada por los pastores mesteños, y por tanto la presencia de rebaños en Madrid, permitía a los alcaldes de la Mesta intervenir en los enfrentamientos que a menudo surgían por los daños que las ovejas causaban en los sembrados. La sentencia de Fernando IV fue la de ratificar la no existencia de cañada alguna en Madrid, y consiguientemente la no intervención de los alcaldes del Honrado Concejo en cuestiones judiciales como la pronunciación de sentencias, la toma de prendas o la posibilidad de abrir nuevas cañadas. El dictamen fue aceptado años después, cuando en 1345 el entonces juez de la Mesta Jordán Garcia reconocía dicha sentencia ${ }^{57}$. Este privilegio a favor de Madrid fue confirmado hasta el final de la Edad Media en momentos y reinados sucesivos, desde mediados del siglo XIV y a lo largo del XV. En 1357 es Pedro I quien lo confirma en sentencia dada por el alcalde don Alemán de Segovia ${ }^{58}$.

Con el comienzo de la nueva dinastía trastámara la situación no va a variar. En 1378, Enrique II ordenaba al entonces alcalde mayor don Juan Martínez de Soto, que guardase esta sentencia ${ }^{59}$. Disposiciones semejantes hallamos reinando Enrique III, en $1398{ }^{60}$ y en $1400{ }^{61}$.

La época de Juan II es sin duda la más interesante en relación a este asunto. Parece evidente que las sentencias anteriores, confirmadas desde

56 Se trata de la cañada real segoviana que atravesaba el norte de la actual Comunidad Autónoma de Madrid; BellosiLlo, 161 y ss.

57 Sentencia prohibiendo el paso de ganados por la villa y su término, donde aparecen insertas las dos cartas de Fernando IV de 1303; T. DOMINGO PALACIO, I, 259 y sS.

5e T. DOMingo PALACIO, I, 345 y ss.

59 La carta está fechada en Valladolid a 14 de febrero de la era de 1416 (año 1378); AV, Secretaría, 2-215-3

60 En este caso se trata de una carta de Enrique III fechada en Madrid el 24 de enero de 1398 por la que hace saber a los justicias de sus Reinos que por el concejo de Madrid le fue querellado que de luengos tiempos acá Madrid tenía el privilegio de no tener cañadas por donde entrasen y saliesen ganados a los extremos ni los alcaldes de la Mesta podían juzgar; AV, Secretaría, 2-215-3.

61 Carta del rey don Enrique III, dada en Valdemoro el 15 de enero de 1400 por la que confirma las sentencias anteriores sobre la exención de cañadas en Madrid; AV, Secretaría, 2-215-3. 
el siglo XIV, habían surtido escaso efecto, y que la presencia de ganado mesteño en Madrid era un hecho. En 1418, Pascual García de Magosa y Juan Fernández de Mansilla, como procuradores diputados por el concejo de la Mesta, reunida en enero de este año en la localidad de Villanueva de Siruela, se presentaban ante las autoridades de Madrid para dar cuenta de las decisiones a las que se había llegado en relación a un problema que no afectaba tan sólo al concejo madrileño, sino a otros municipios como Guadalajara, Zorita, Brihuega, Hita y Fuentidueña, en relación al paso del ganado. Se trataba de llegar a un acuerdo entre ambas partes que no perjudicase a nadie, y que pudiese poner fin al conflicto. De esta forma se llega al convenio de 1418, documento de excepcional valor para entender las relaciones Madrid-Mesta en el contexto de la ganadería foránea. El acuerdo se hace por: «vivir en paz y en sosiego e aver buen amorío con la dicha villa e su tierra e porque pudieren pasar los ganados que fueren a los extremos a placencia e voluntad de la dicha villa e tierra...” 62 .

Los puntos más importantes del convenio se refieren a las propuestas de la Mesta y de Madrid. Expondremos en primer lugar las de la Mesta, las cuales, excepto algunos casos, fueron aceptadas:

\section{Convenio Madrid-Mesta de 1418}

1. Que Madrid tuviese a bien reparar los puentes por donde pasasen los ganados.

2. Que Madrid diese paso en los términos de la villa a cada rebaño que pasare durante cuatro días con sus respectivas noches.

3. Que de los ganados que pasasen por la villa y su término e hiciesen daño en los panes y viñas y dehesas y prados de guadaña, sólo fuesen embargados uno o dos de los que hiciesen el daño y que el mismo fuese apreciado por dos hombres buenos juramentados.

4. Que la villa de Madrid pusiese dos personas para coger la renta que se hubiese de pagar por los rebaños mesteños y que la misma se destinase al reparo de los puentes del término madrileño.

En contrapartida Madrid exigía nueve condiciones que el Honrado Concejo se debía comprometer a cumplir. Entre ellas estaban:

62 La carta de procuración a los diputados por la Mesta enviados a Madrid está dada el 14 de enero de 1418, sólo algunos días después de celebrada la junta de la Mesta en Villanueva de Siruela el 8 de enero del mismo año; AV, Secretaria, 2-358-55. 
1. Que los ganados que pasasen por el puente de Biveros trajesen albalaes de Daganzo sobre el número de ovejas de cada rebaño con el fin de safisfacer el impuesto a razón de cincuenta maravedís por millar, imponiendo penas a quienes no lo declarasen.

2. Que el ganado vacuno que pasase por el término de Madrid pagase tres dineros por cabeza.

3. Que todo el ganado que pasase por los términos de Madrid, tanto por el puente de Biveros como por el de Manzanares como por el de Villanueva, se haga saber a las personas que fuesen puestas por la villa para recaudar los derechos pertinentes.

4. Que todos los pastores y rabadanes a la entrada del concejo pagasen lo concerniente a cada rebaño, a razón de cincuenta maravedís el millar de cabezas.

5. Que en virtud de la renta del herbaje y pasaje y del adobo de los puentes no se entienda pueda hacerse cañada por la villa ni por su tierra.

6. Que todos los privilegios y sentencias que la villa de Madrid tiene estén en fuerza y valor y así ningún vecino de Madrid acuda al llamamiento de los alcaldes de la Mesta.

7. Que si no fuese satisfecha la renta del herbaje y pasaje que las autoridades del concejo de Madrid lo puedan demandar, así de lo que rindiese la renta como de la pena, tanto a la entrada como a la salida del concejo.

8. Que los pastores y rabadanes pasasen por el término de Madrid guardando prados, dehesas, viñas y panes y si algún daño hiciesen pagasen la pena según las ordenanzas del concejo de Madrid.

9. Que si se produjesen contiendas y debates entre los vecinos de Madrid y los pastores de la Mesta que sean los regidores de Madrid quienes determinen dichas contiendas.

El convenio en su conjunto intenta preservar tanto al ganado como a los cultivos de cualquier acción que pudiera ir en contra de los intereses de ambas partes.

Conviene señalar algunas cuestiones relacionadas tanto con el tránsito de ovejas como con aspectos fiscales. El documento señala unos topónimos determinados que establecen claramente el recorrido de los rebaños y su procedencia. De esta forma el término madrileño aparecía recorrido por dos ramales de la cañada real segoviana ${ }^{63}$ y la conquense. El primero bajaba desde Manzanares el Real y Collado Villalba, y entraba en Madrid por los términos de Las Rozas, Majadahonda y Pozuelo, para llegar a Alcorcón donde en 1442 se cobraba el portazgo del ganado, que pasaba por el puerto merchanego situado en dicha aldea ${ }^{64}$. Desde Alcorcón el

63 A. Diaz Martínez, La cañada real segoviana a su paso por Madrid, Madrid, 1987.

64 AV, MINUTAS... I. f. 35V. 
ramal abandonaba la jurisdicción madrileña para continuar hacia Móstoles y las tierras de Escalona, donde volvía a unirse a la cañada real segoviana.

El segundo ramal, al que hace mención el convenio, es el que descendía por el valle del Jarama procedente también de la cañada segoviana, pero en dirección a la cañada real conquense, por lo que desde Daganzo llegaba a Madrid por el puente de Biveros, y su recorrido ya lo describimos al hablar de las cañadas. Tenemos testimonios de un sector de este ramal en las sentencias sobre términos que el licenciado Díaz de Montalbo dio en 1453, referente al ejido de la Torre de Ivan Crespín, lugar conocido también como la Torrecilla, situado junto al río Manzanares, y que en esta fecha aparece como despoblado. La intervención del licenciado, nombrado juez de términos en Madrid por el rey, vino determinada por la intromisión que los renteros del regidor madrileño Pedro Suárez hacían en dicho lugar, en donde el poderoso caballero tenía sus heredades. En la sentencia se hace mención a la cañada para el paso de ganados forasteros con el fin de que fuese amojonada, con la participación de los vecinos de Vallecas, Getafe y Pinto, cuyos términos atravesaba. Todo apunta a que dicha intervención estuvo motivada por el estrechamiento del ramal por los campesinos. De esta forma se señala que: «La cannada que pasa por çerca del dicho logar por do van y vienen los ganados estrangeros, que estava grand parte della asi de la parte del rrio contra el monte de Vallecas commo de la parte contra el dicho logar La Torre, que estava muy ensangostada e estrecha de commo solia ser...". Al final se impusieron unas medidas que debían ser respetadas, y que establecían el ancho de la cañada en treinta pasos, tanto en una parte del río como en la otra ${ }^{65}$.

Otra cuestión relacionada con el paso de los rebaños es la que concierne a la reparación y mantenimiento de los puentes. De estos se citan tres en el documento de 1418: Biveros, Manzanares y Villanueva. Sabemos que en el primero y en el último se había establecido el portazgo, pues ambos se situaban en el límite de la jurisdicción de Madrid. Son las autoridades madrileñas quienes se harán cargo de ello, según una de las cláusulas del convenio, destinando un porcentaje del dinero recaudado en la renta del paso del ganado para tal fin. El desgaste habitual que sufría la

65 La sentencia sobre el ejido de la Torre de Ivan Crespín y la cañada que pasaba por el lugar está dada en el mismo lugar, el día 5 de noviembre de 1453 ante el licenciado Alonso Díaz de Montalbo, con la presencia de Alfonso de Salmerón como procurador del concejo de Madrid, y de Antón Juan como procurador del caballero Pedro Suárez de Toledo. La información dada al juez sobre la cañada estuvo a cargo de Pedro Gómez, Juan Martinez Pingarrón y Pedro Martín del Álamo, junto a otros vecinos de Getafe; AV, Secretaría, 3-189-6. 
estructura de estos puentes ${ }^{66}$, no sólo se debía al paso del ganado mesteño, cuyo tránsito se reducía a unos días concretos del año, sino básicamente al trasiego de personas y mercancías, pues tanto Biveros ${ }^{67}$ como Villanueva ${ }^{68}$ se situaban en importantes rutas del comercio interregional ${ }^{69}$. Por último, según el convenio, el paso del ganado tenía establecido un límite de tiempo que en el caso de cada rebaño no podía superar los cuatro días de duración. Este tiempo es el que se consideraba apropiado para que las ovejas atravesasen tranquilamente el término de Madrid pudiendo aprovecharse de sus pastos. Pasado el mismo los pastores incurrían en pena, pues una prolongada permanencia iba en detrimento tanto del concejo como de los mismos rebaños mesteños.

Los aspectos fiscales resultan también importantes en relación al número de ovejas y a los beneficios que Madrid podía obtener. La renta del servicio y montazgo indica por sí misma su propia naturaleza, en cuanto al pago de unos derechos en compensación por la hierba que el ganado consumía y las molestias que ocasionaba ${ }^{70}$. Se trataba del gravamen más importante, del que la Corona obtenía pingües beneficios. En principio los estantes quedaban exentos de este impuesto, que los propietarios de ganado trashumante debían satisfacer. Afectaba pues a la marcha de los rebaños en su tránsito por diversos términos y jurisdicciones, tanto realengas como señoriales, en razón del aprovechamiento de los pastos (montazgo).

El servicio exigía a la ida del ganado cinco ovejas o carneros con sus crias por cada mil, más tres maravedís en concepto de guarda del ganado. Al regreso se debían pagar cuatro maravedís por aquellos corderos que hubiesen nacido en la veranada. Por montazgo se entendia el derecho a pasto de las ovejas en las treinta y dos circunscripciones, tanto de realengo como de señorío, en que se dividía el territorio castellano, con un canon fijo en relación a la calidad de la hierba. El impuesto se satisfacía en especie, y variaba según los territorios. En general se solía liquidar por

66 M. A. MOnturiol González, "Vías de comunicación y hacienda local en Madrid en el último tercio del siglo XV", Caminos y caminantes por las tierras del Madrid Medieval, LAYA, 12, Madrid, 1994, 141-164, 149.

87 En los padrones de la tierra de Madrid de 1413 y 1414, Biveros junto a Quintana aparecen como lugares despoblados; AV, Secretaría, 4-169-55.

68 Villanueva con el Burrillo aparecen en los padrones de 1413 y 1414 como lugares de la jurisdicción de Madrid que aún existían; AV, Secretaría, 4-169-55.

69 T. Puñal Fernández, "Caminos y mercaderes en el concejo de Madrid", Caminos y caminantes por las tierras del Madrid Medieval, LAYA, 12, Madrid, 1994, 117-123, 120.

70 M. V. Gómez MAMPASo, "Notas sobre el Servicio y Montazgo. Orígen y Evolución Histórica a lo largo de la Edad Media", Historia de la Hacienda Española (Antigua y Medieval). Homenaje al Profesor García de Valdeavellano, Madrid, 1982, 301-318. 
cada mil cabezas y el importe se situaba entre las catorce y las dos ovejas ${ }^{71}$. En 1418 su cuantía se estableció en cincuenta maravedís que los pastores o propietarios debían pagar a los portazgueros del puente de Biveros por cada mil ovejas ${ }^{72}$. En 1472 hemos hallado referencias al servicio y montazgo en el pleito que el arrendador de este año, y un vecino de la aldea de Fregacedos, trataron sobre el impago del mismo ${ }^{73}$. Igualmente en 1469 Enrique IV concedía al monasterio de santo Domingo el Real doscientos carneros situados en la renta del servicio y montazgo que se debían entregar puestos por los arrendadores en los puertos, privilegio que sería confirmado más tarde por los Reyes Católicos en $14988^{74}$.

La renta del paso del ganado fue también una de las más importantes del conjunto de los propios municipales. Las primeras referencias que hemos hallado sobre su arrendamiento son de 1445. A comienzos de octubre de este año, y por tanto coincidiendo con la estancia de los rebaños en Madrid, el mercader Francisco González de Madrid ofrecía por su arrendamiento dieciséis mil maravedís. Las condiciones estipulaban que en caso de puja el mercader ganase quinientos maravedís de prometido que debian ser cargados a quien la realizase ${ }^{75}$. Desconocemos quien se hizo cargo de esta renta en años sucesivos, y por qué cantidad. Sin embargo a partir del reinado de Enrique IV, y más concretamente en el año 1465 , las cuentas de propios concejiles, que el mayordomo municipal debía ofrecer como justificante en la gestión de su cargo, nos informan de arrendadores y cifras, aunque bien es verdad que de forma interrumpida. En el primero de los años el judío madrileño y mercader Menahen Çidre, la arrendaba por la cantidad de diez mil quinientos maravedis, ofreciendo como fiador a Juan de Madrid, vecino de la villa ${ }^{76}$. En 1466 las

71 Se señalan tres tipos de demarcaciones: Las superiores que exigían entre 8-14 ovejas por 1000; las regulares entre 5-6 por 1000 y las inferiores entre 2-3 por 1000; RUIz MARTíN, 273 y SS.

72 La excepción a este canon se produjo precisamente el mismo año en que entró en vigor el convenio, a partir del día de san Miguel, 29 de septiembre, ya que se señala que en este año no pasaron los ganados para ir a los extremos por pasada sino por tornada, por lo que se debían pagar tan sólo treinta maravedís por millar; AV, Secretaría, 2-358-55.

73 Se trata de García de Montalbán, vecino de Madrid, que en este litigio había designado como juez de abenencía a Alonso González Romano, alcalde de Madrid, en la demanda del servicio y montazgo contra Pedro González, vecino de Fregacedos, por la que éste debía pagar al arrendador quinientos maravedís, y García de Montalbán devolver al deudor las prendas que le habían sido tomadas por ello. El alcalde, reconciliadas las partes, dio por terminado el pleito; AV, MINUTAS... III, f. $491 v$.

74 Privilegio dado en Madrid el 10 de noviembre de 1469; AHN., Clero, carp., 1367, $n^{9} 9$.

75 Martes, 5 de octubre de 1445; AV, MINUTAS... I, f. 274r.

76 AV, Secretaría, 3-79-29. La misma información se recoge en los libros de acuerdos del concejo: «la rrenta del paso del ganado estremeño que pasa por Madrit e su tierra e ha de pasar este año, con la tornada que será el año venidero...e obligaronse de pagar los dichos diez mill e qui- 
cuentas de propios no nos informan del arrendador. Sin embargo por otras informaciones sabemos que se trata del mismo, que en este caso aparece actuando junto a su mujer, doña Jamila, ofreciendo ambos como arrendadores al mayordomo concejil diez mil quinientos maravedís, la misma cantidad que el año anterior. En el documento se habla del «paso del ganado estremeño ques del conçejo de Madrid". Así mismo se informa que la renta se refiere tanto a la ida como a la vuelta del ganado, y que los mismos se hacían responsables de cualquier incidencia, de forma que el concejo no produciría ningún descuento en la cantidad acordada. La entrega del dinero se estructuraba en dos pagas. Una a fines de octubre, y la otra a final de noviembre, justo cuando los rebaños habían comenzado la trashumancia ${ }^{77}$.

En la década de los setenta hallamos información para los años 1471, 1472 y 1473. En 1471 los arrendadores eran Manuel Rodríguez, escribano público, vecino de Madrid, y el también escribano Ruy Fernández. Sin embargo el primero hizo traspaso de la mitad de la renta en Pedro González Candí, vecino de la villa ${ }^{78}$. En este caso González Candí y Ruy Fernández debían satisfacer veinte mil maravedís, a razón de diez mil maravedís cada año, pues el arrendamiento se hizo para 1472 y 1473 . En el documento se expresan las mismas condiciones que ya hemos señalado, y se hace mención al acuerdo al que el concejo de Madrid había llegado con la Mesta ${ }^{79}$.

Renta del paso del ganado en Madrid

\begin{tabular}{ccc}
\hline AÑO & ARRENDADOR & CANTIDAD \\
\hline 1445 & Francisco González & $16.000 \mathrm{mrs}$. \\
1465 & Menahen Çidre & $10.500 \mathrm{mrs}$. \\
1466 & Menahen Çidre y Jamila & $10.500 \mathrm{mrs}$. \\
1471 & P. Gzez. Candi y Ruy Fernández & $10.000 \mathrm{mrs}$. \\
1472 & P. Gzez. Candi y Ruy Fernández & $10.000 \mathrm{mrs}$. \\
1473 & P. Gzez. Candi y Ruy Fernández & $10.000 \mathrm{mrs}$. \\
\hline
\end{tabular}

nientos maravedís, la mitad en fin deste mes de otubre e la otra meitad en fin de novienbre primero que viene...”; Sesión del concejo de 24 de octubre de 1465; LACM., I, 9.

77 Conviene hacer notar que tanto los protocolos como el libro de acuerdos del concejo nos informan que la cifra del arrendamiento fueron 10.500 maravedis; AV, MINUTAS... III, f. 223r y LACM., I, 9 y ss., mientras que las cuentas de propios señalan esta cantidad en 15.000 maravedis; AV, Secretaría, 3-79-29; Pensamos que la cifra correcta es la que ofrecen los protocolos y el libro de acuerdos, al ser más acorde con las cifras de años posteriores.

${ }_{78}$ Como tal aparece junto a Ruy Fernández en las cuentas de propios del concejo ofreciendo 10.000 maravedís; AV, Secretaría, 3-79-29.

79 Viernes, 5 de octubre de 1472; AV, MINUTAS... III, f. 516v-517r. 
En el análisis del cuadro anterior observamos una cierta uniformidad en el arrendamiento y cobro de esta renta. Los quinientos maravedís de más, que aparecen en 1465 y 1466 con respecto a los diez mil en que parece que estaba fijada esta renta, se deben sin duda a un prometido, lo que indica que en dichos años hubo pujas, rematándose la renta en las personas señaladas. El caso de 1445, con dieciséis mil maravedís, puede interpretarse como un primer ofrecimiento que pudo ser pujado o no, o como un incremento de dicha renta con respecto al periodo enriqueño. De todas formas lo aislado del caso, cronológicamente hablando, no nos permite llegar a conclusiones como la de un posible aumento de la cabaña ganadera, y ovina en particular, en el reinado posterior. A cambio de todo esto se exigían responsabilidades a los pastores y sus ayudantes o rabadanes en relación a sembrados y pastos vedados, así como el respeto por parte de la Mesta a los privilegios de Madrid referentes a la no existencia de cañadas, y a la intromisión de los alcaldes mesteños en las incidencias provocadas por los rebaños y sus pastores, cuya resolución atañía exclusivamente a los regidores y justicias madrileños.

El convenio de 1418 tuvo en principio una vigencia de diez años, siendo preciso que a partir de 1428 el concejo de Madrid desease o no renovarlo. Sin embargo, parece ser que fue la Mesta la que tomó la decisión de actuar libremente sin considerar el acuerdo con Madrid. Este hecho se deduce del nombramiento en diciembre de 1428, algunos meses después de expirar el convenio, de un nuevo alcalde mesteño para Madrid en la persona de Pedro Ruiz de Gaona. Tal designación se hizo por don Íñigo López de Mendoza, duque del Infantado, que actuaba en nombre y con poderes de su sobrino Gómez Carrillo, menor de edad, que ostentaba el título honorífico de alcalde entregador mayor de la Mesta. Hay que señalar que el linaje de los Carrillo entronca con el de los Albornoz en la figura de Gómez Carrillo, el Viejo, quien en 1427 figura como camarero de Juan II y alcalde mayor de los hidalgos de Castilla, siendo también desde el reinado de Juan I alcalde mayor de las Mestas y cañadas. El sucesor en el cargo fue su nieto Gómez Carrillo de Albornoz, quien tan sólo con seis años recibió tal título de la reina madre Catalina de Láncaster en $1417^{\circ 0}$. La decisión de Madrid de oponerse al alcalde, esgrimiendo sus antiguos privilegios, motivó un nuevo fallo favorable por el que se eximía a los alcaldes mesteños de cualquier jurisdicción ${ }^{81}$. De todas formas el conflicto sobre

80 F. M. Martínez Fronce, Una cuadrilla mesteña: La de Cuenca, Cuenca, 1989, 30 y ss.

81 La sentencia es dada por el propio alcalde mesteño Pedro Ruíz de Gaona alegando no haber cañadas en Madrid, y por tanto no tener los alcaldes de la Mesta ninguna jurisdicción en el concejo; AV, Secretaría, 2-358-55. 
las competencias de los alcaldes de la Mesta en los distintos territorios concejiles, continuó durante todo el reinado de Juan II. En 1431 el rey enviaba misivas a las distintas villas y ciudades castellanas recordando cómo Gómez Carrillo era alcalde mayor de la Mesta y que los oficiales y alcaldes por él designados debían ser respetados y aceptados, según las ordenanzas reales otorgadas y confirmadas desde la época de su antecesor Alfonso $X{ }^{82}$. Parece ser que desde esta fecha hay una decidida voluntad por parte de las autoridades reales en que la institución mesteña reafirme su autoridad sobre los municipios. De esta forma en 1432, una vez que Gómez Carrillo de Albornoz había alcanzado la mayoria de edad, se produce el nombramiento de Gómez Fernández de Horozco, vecino de Guadalajara, como alcalde de la Mesta en el arcedianazgo de Madrid, para que: "en todas las villas e logares del dicho arçedianasgo... podades requerir e abrir cannadas e veredas e exidos e abrevaderos e açegaderos por donde andan los ganados e levar calonnas...» ${ }^{83}$. Es evidente que con esta decisión se estaban vulnerando muchos de los principios del convenio de 1418. En todo caso la Mesta se fue haciendo cada vez más poderosa pues había muchos intereses en juego, parte de los cuales tenían que ver con el comercio de la lana. Sin embargo se puede afirmar que el conflicto Madrid-Mesta, puesto de manifiesto sobre todo durante el reinado de Juan II, no fue sólo un problema económico, sino también señorial. El que fuesen personas emparentadas con la casa del Infantado las que detentaban el cargo de alcaldes mayores provocó suspicacias en un concejo como el de Madrid enfrentado con este linaje por motivos territoriales. Es posible que se pensase que la designación de alcaldes para Madrid por el sobrino de íñigo López de Mendoza, suponía un cierto control señorial a la hora de tomar decisiones en asuntos económicos que podían favorecer una ganadería foránea castellana de grandes rebaños señoriales en detrimento de la propia cabaña, tanto estante como trashumante. En definitiva parece ser que se trata de un conflicto de intereses en el que afloran ciertas dosis de proteccionismo local. Por otro lado todo ello es un buen exponente de la importancia que la ganadería ovina llegó a alcanzar en Castilla, y en Madrid en particular, reflejo de unas estructuras económicas de mercado en las que la lana es el factor principal.

82 En su carta el rey habla de los poderes que usaron sus otros alcaldes mayores y sus lugartenientes entre los que cita a Juan Ortiz Calderón, García Alvarez de Toledo, Ruy Gutiérrez de Finestrosa, Iñigo López de Horozco y Gómez Carrillo, el Viejo, abuelo del actual alcalde mayor; AV, Secretaria, 2-358-53.

83 Dicha designación se hace en nombre de Gómez Carrillo como alcalde entregador mayor de la Mesta, y está dada en Chinchilla el 4 de junio de 1432; AV, Secretaría, 2-358-53. 


\section{LOS PROPIETARIOS DE OVEJAS}

El estudio de la ganadería ovina debe tener en cuenta también a los propietarios de ovejas, por cuanto ello nos permitirá conocer muchos aspectos concernientes a la producción y el comercio de la lana. En este sentido hemos creído conveniente iniciar este análisis basándonos en la información que las mismas fuentes ofrecian, al señalar casi siempre a las personas de quienes eran los rebaños. Sin embargo debemos tener en cuenta algunas salvedades. En primer lugar, aunque bien es verdad que la documentación señala a estas personas, es a veces bastante difícil distinguir cuando se trata del propietario real o de un arrendatario. Expresiones como "ovejas suyas de su guarda e encomienda...", son muy frecuentes pero al mismo tiempo ofrecen una cierta ambigüedad. Es sabido que en la Edad Media fue usual el distinguir dos tipos de propiedad, la útil y la eminente. La primera como forma de usufructo y la segunda como propiedad legal o jurídica de un bien mueble o inmueble ${ }^{84}$. El uso de la propiedad eminente podía implicar también la útil, y viceversa. Sin embargo consideraremos como propietarios eminentes, no sólo a todas aquellas personas que aparecían claramente como tales, sino a las que ofrecían alguna duda en razón de la ambigüedad contextual que hemos señalado. Hemos podido observar a través del análisis de más de un centenar de noticias sobre ovejas y rebaños que la propiedad útil de los mismos, es decir cuando se trata del arrendador, se expresa sencillamente con la fórmula «pastor de...", indicativa del tipo de detente en la propiedad de las ovejas.

Es frecuente señalar el predominio de grandes propietarios, miembros de las oligarquias urbanas, nobleza o clero ${ }^{85}$, frente a una minoría de pequeños propietarios, básicamente campesinos ${ }^{86}$. Sin embargo recientes

84 Sobre este tema se pueden consultar algunos trabajos enfocados tanto desde un punto de vista jurídico, en relación al derecho, como simplemente histórico. En cuanto al primer punto está el artículo de L. Garcia de ValdeAvellano, "Bienes muebles e inmuebles en el derecho medieval español", CHE, IX (1949). Para los trabajos de enfoque histórico ver C. ARGENTE DEL CAstillo-OCAÑa, "Bienes muebles e inmuebles de pequeños labradores y artesanos en Jaén (1511)", Actas del III coloquio internacional de historia medieval andaluza, Jaén, 1984, 199-210. También se puede consultar a M. C. CARLE, "Gran propiedad y grandes propietarios", CHE, LVII-LVIII (1973), 1-224.

85 De los monasterios madrileños sabemos que el de santo Domingo el Real era propietario de ganado, además de tierras e inmuebles, mientras que el de san Jerónimo, fundado por Enrique IV, tenía por privilegio real la concesión anual de doscientos carneros, según consta en el fechado en Valladolid el 10 de diciembre de 1464; AGS., Privilegios Reales, 58-61.

86 En este sentido se expresan autores como R. Pastor siguiendo a V. Vives afirmando la existencia de propietarios de enormes rebaños que controlaban la Mesta. Sin embargo autores como J. Klein abundan en la existencia también de pequeños y medianos propietarios con una organización más democrática; PASTOR BAÑos, "La lana en Castilla y León... ", 364. 
estudios de historia local han permitido sino desmentir este esquema por lo menos matizarlo ${ }^{87}$. En el caso madrileño la existencia de rebaños de tipo medio constata la existencia, junto al sector de la oligarquía urbana de regidores y caballeros, de un número abundante de pequeños y medianos propietarios de la tierra. Algunos de ellos constituyen una importante oligarquía rural de labradores enriquecidos o pecheros mayores ${ }^{88}$ con una posición social y económica bastante acomodada. Este hecho ha sido también puesto de manifiesto para otros ámbitos no muy lejanos a Madrid, como es Segovia ${ }^{89}$. Hemos querido ofrecer una relación de estos propietarios haciendo una ordenación por sesmos y aldeas en la que se indica el año y el número de ovejas correspondientes.

Propietarios de ovejas

\begin{tabular}{|c|c|c|}
\hline & $\begin{array}{c}\text { SESMO DE ARAVACA } \\
\text { ARAVACA }\end{array}$ & \\
\hline AÑO & PERSONAS & OVEJAS \\
\hline 1464 & A. García el Blanco & 100 \\
\hline 1466 & Juan Martínez & 300 \\
\hline \multicolumn{3}{|c|}{ POZUELO } \\
\hline AÑO & PERSONAS & OVEJAS \\
\hline 1444 & D. Fernández, pastor & 300 \\
\hline 1463 & J. de Carabanchel & 300 \\
\hline 1472 & A. Fernández Vicente & 400 \\
\hline 1473 & P. Gutiérrez & - \\
\hline \multicolumn{3}{|c|}{ ALCORCÓN } \\
\hline AÑO & PERSONAS & OVEJAS \\
\hline 1444 & Alonso, pastor & 150 \\
\hline 1449 & A. García Mesurado & - \\
\hline 1453 & P. de Manzanares & carneros \\
\hline 1471 & J. Sánchez de J. Ibáñez & 350 \\
\hline 1473 & A. Garcia Escobar & 400 \\
\hline
\end{tabular}

E7 De esta forma se pronuncian entre otros para el caso de Córdoba, CORDOBA DE LA LLAVE, La industria medieval de Córdoba, Córdoba, 1990, donde señala la existencia de miembros de la nobleza urbana, artesanos y labradores como propietarios de ganado, 36 . Lo mismo se refiere para el caso de Soria, M. Diago HERnANDO, "Aprovechamiento de baidíos y comunales en la Extremadura Soriana a fines de la Edad Media", $A E M, 20$ (1990), 413-434. En este artículo el autor señala que un alto porcentaje de los ganados que quedaban en invierno pertenecian a pequeños propietarios campesinos que no contaban con demasiados recursos para mantenerios, 425 .

BB J. L. MARTín Rodriguez, "La sociedad media e inferior de los reinos hispánicos", Anuario de Estudios Medievales, 7 (1970-1971), 555-576.

89 M. AsEnJo GONZALEZ, "Labradores ricos: Nacimiento de una oligarquía rural en la Segovia del siglo Xv", En La España Medieval, 12 (1989), 63-85. 
Propietarios de ovejas (continuación)

\begin{tabular}{|c|c|c|}
\hline \multicolumn{3}{|c|}{ CARABANCHELES } \\
\hline AÑO & PERSONAS & OVEJAS \\
\hline 1442 & J. García Zofio & 150 \\
\hline 1444 & J. Robredo & 30 \\
\hline 1444 & J. Alonso & 300 \\
\hline 1445 & J. García Zofio & 300 \\
\hline 1445 & B. Sánchez Rodajo & 15 \\
\hline 1448 & A. García Patraleño & - \\
\hline 1449 & P. Martín, pastor & 300 \\
\hline 1449 & Mujer de Nuño Sánchez & - \\
\hline 1449 & Nicolás García & - \\
\hline 1449 & P. Gómez & - \\
\hline 1452 & J. Alonso Maroto & 150 \\
\hline 1463 & B. Sánchez Rodajo & 200 \\
\hline 1472 & M. Aguado & 400 \\
\hline 1472 & A. de Beteta & - \\
\hline 1472 & A. Rodajo & 200 \\
\hline 1473 & P. Martín, tejedor & 20 \\
\hline 1473 & María, la Zofia & 400 \\
\hline \multicolumn{3}{|c|}{$\begin{array}{c}\text { SESMO DE MADRID } \\
\text { MADRID }\end{array}$} \\
\hline AÑO & PERSONAS & OVEJAS \\
\hline 1445 & G. Ruiz & 100 \\
\hline 1447 & J. de la Puerta & 500 \\
\hline 1447 & P. de la Puerta & - \\
\hline 1447 & D. de Paredes, regidor & - \\
\hline 1449 & P. García Villoslada & - \\
\hline 1449 & P. de Lusón, regidor & - \\
\hline 1449 & Prior de San Martín & 300 \\
\hline 1449 & J. Alonso, escribano & 600 \\
\hline 1449 & A. Garcia de Hurosa & 600 \\
\hline 1449 & A. de San Pedro & carneros \\
\hline 1449 & Fraym Aben Xuxe & - \\
\hline 1453 & Menahen Çidre & - \\
\hline 1463 & B. del Valle & 100 \\
\hline 1463 & P. Suárez, comendador & - \\
\hline 1464 & Maestro Hamet Merino & carneros \\
\hline 1471 & J. Alonso & 200 \\
\hline 1471 & Maestro Hazan & corderos \\
\hline 1471 & doña Jamila & - \\
\hline 1471 & Garcia González, platero & - \\
\hline 1471 & F. Díaz & - \\
\hline 1472 & P. Martín, tejedor & 400 \\
\hline 1472 & Maestro Abdallá Toledano & 600 \\
\hline 1472 & A. Rodríguez de Mora & 400 \\
\hline 1472 & F. de San Pedro & - \\
\hline
\end{tabular}


Propietarios de ovejas (continuación)

\begin{tabular}{|c|c|c|}
\hline \multicolumn{3}{|c|}{$\begin{array}{l}\text { SESMO DE MADRID } \\
\text { MADRID }\end{array}$} \\
\hline AÑO & PERSONAS & OVEJAS \\
\hline $\begin{array}{l}1472 \\
1473 \\
1473 \\
1473 \\
1473\end{array}$ & $\begin{array}{l}\text { Mujer de P. de Cuadros } \\
\text { P. y Juan Palomino } \\
\text { P. Díaz } \\
\text { F. de Torrejón } \\
\text { D. del Barranco }\end{array}$ & $\frac{250}{400}$ \\
\hline \multicolumn{3}{|c|}{$\begin{array}{c}\text { SESMO DE VALLECAS } \\
\text { VALLECAS }\end{array}$} \\
\hline AÑO & PERSONAS & OVEJAS \\
\hline $\begin{array}{l}1444 \\
1449\end{array}$ & $\begin{array}{l}\text { García Martín } \\
\text { A. García }\end{array}$ & $\begin{array}{r}100 \\
15\end{array}$ \\
\hline \multicolumn{3}{|c|}{ HORTALEZA } \\
\hline AÑO & PERSONAS & OVEJAS \\
\hline $\begin{array}{l}1444 \\
1444 \\
1471 \\
1471\end{array}$ & $\begin{array}{l}\text { P. Martín } \\
\text { J. García de Coslada } \\
\text { J. de Coslada } \\
\text { P. García de Ayuso }\end{array}$ & $\begin{array}{r}30 \\
33 \\
150 \\
200\end{array}$ \\
\hline \multicolumn{3}{|c|}{ REJAS } \\
\hline AÑO & PERSONAS & OVEJAS \\
\hline $\begin{array}{l}1449 \\
1452\end{array}$ & $\begin{array}{l}\text { G. Fernández, pastor } \\
\text { E. Sánchez }\end{array}$ & $\underset{600}{-}$ \\
\hline \multicolumn{3}{|c|}{ FUENCARRAL } \\
\hline AÑO & PERSONAS & OVEJAS \\
\hline $\begin{array}{l}1471 \\
1472\end{array}$ & $\begin{array}{l}\text { J. Sánchez Guerrero } \\
\text { P. del Valle }\end{array}$ & 400 \\
\hline \multicolumn{3}{|c|}{ VICÁLVARO } \\
\hline$\overline{A N N O}$ & PERSONAS & OVEJAS \\
\hline $\begin{array}{l}1472 \\
1472\end{array}$ & $\begin{array}{l}\text { Mujer de J. Martín } \\
\text { A. Sánchez, pastor }\end{array}$ & 200 \\
\hline \multicolumn{3}{|c|}{$\begin{array}{c}\text { SESMO DE VILLAVERDE } \\
\text { VILLAVERDE }\end{array}$} \\
\hline AÑO & PERSONAS & OVEJAS \\
\hline $\begin{array}{l}1444 \\
1445 \\
1449 \\
1449 \\
1452 \\
1466 \\
1471 \\
1472\end{array}$ & $\begin{array}{l}\text { A. Martín } \\
\text { Pascual García } \\
\text { La Zamorana } \\
\text { Antón Garcia } \\
\text { Alvar Martínez } \\
\text { Francisco Remixaco } \\
\text { Domingo Fernández } \\
\text { J. Mtn. de la Vieja }\end{array}$ & $\begin{array}{c}500 \\
200 \\
60 \\
500 \\
100 \\
\text { borregos } \\
\text { corderos } \\
300\end{array}$ \\
\hline
\end{tabular}


La ganadería lanar en Madrid y su tierra durante la Edad Media

Propietarios de ovejas (continuación)

\begin{tabular}{|c|c|c|}
\hline \multicolumn{3}{|c|}{ GETAFE } \\
\hline AÑO & PERSONAS & OVEJAS \\
\hline 1442 & P. Sánchez & 140 \\
\hline 1449 & P. Fdez. Pingarrón & 350 \\
\hline 1449 & P. Sánchez Sacristán & - \\
\hline 1452 & M. Martínez del Pozo & 500 \\
\hline 1452 & J. Martín Pingarrón & carneros \\
\hline 1460 & B. Ricote & 500 \\
\hline 1463 & J. González Donayre & 300 \\
\hline 1464 & A. García Crespo & 300 \\
\hline 1466 & A. Martínez Pingarrón & 450 \\
\hline 1466 & J. González Donayre & 440 \\
\hline 1466 & J. Cabezudo & - \\
\hline 1471 & M. de Overa & 200 \\
\hline 1471 & M. Mtnez. de Arriba & 150 \\
\hline 1472 & J. de Merlo & 200 \\
\hline 1472 & M. Martín Obrero & 200 \\
\hline 1472 & P. Prieto & 150 \\
\hline 1472 & M. Mtnez. de Arriba & 250 \\
\hline 1472 & A. Mtnez. Pingarrón & 600 \\
\hline 1472 & J. de Olias & 500 \\
\hline 1472 & J. Gasco & 45 \\
\hline 1472 & M. García, la Dorada & - \\
\hline 1473 & A. Mtnez. Pingarrón & 300 \\
\hline 1473 & J. de Villaverde & 400 \\
\hline \multicolumn{3}{|c|}{ PINTO } \\
\hline AÑO & PERSONAS & OVEJAS \\
\hline 1444 & J. de Escobar & 300 \\
\hline 1466 & P. Gutiérrez & - \\
\hline 1466 & A. Granado & - \\
\hline \multicolumn{3}{|c|}{ LEGANÉS } \\
\hline AÑO & PERSONAS & OVEJAS \\
\hline 1460 & M. Pérez Vadecacho & 500 \\
\hline 1462 & M. Fernández Aguado & 300 \\
\hline 1462 & Benito Honguero & - \\
\hline 1471 & La Aceitera & 60 \\
\hline
\end{tabular}

La distribución de propietarios por aldeas nos permite conocer en qué zonas de Madrid predominaban los rebaños, al tiempo que se nos ofrece un estudio prosopográfico de las distintas familias poseedoras de ovejas. Conviene poner de manifiesto sus características sociales y económicas para entender la formación de estas oligarquías rurales madrileñas como clase media emergente. 
Comenzaremos, siguiendo el mismo orden del cuadro anterior, por el sesmo de Aravaca con las cinco aldeas de las que tenemos información, Aravaca, Pozuelo, Alcorcón y los Carabancheles.

En Aravaca se menciona a Juan Martínez que en 1466 poseía un rebaño de trescientas ovejas. En este mismo año aparece también como propietario de tierras de sembradura, contratando a jornaleros y mesegueros para las labores de la siega ${ }^{90}$.

En Pozuelo encontramos a Alonso Fernández Vicente quien en 1472 tenía reses. La familia de los Vicente es el exponente de la existencia en dicha aldea de un grupo de labradores de clase media propietarios de bienes y disfrutarios de tierras en contratos de arrendamiento ${ }^{91}$.

En Alcorcón la documentación nos presenta a dos familias representativas del lugar, de entre las cuales destacan los Mesurado. Miembros de esta familia son Juan Alonso Mesurado, Alonso García Mesurado, hijo del anterior, junto a sus hermanos Diego García y Martín García Mesurado. Alonso García, el primogénito, poseía tierras y ganado. De esta forma aparece en 1449 diezmando por sus corderos a la iglesia de Alcorcón, lo que indica la tenencia de ovejas ${ }^{92}$. En el mismo año él y su mujer venden algunas viñas ${ }^{93}$, y es posible que disfrutase de algún contrato de arrendamiento de tierras en relación a don Alfonso Álvarez de Toledo, contador mayor y secretario real, miembro destacado de la nobleza madrileña y poseedor de casas, tierras y ganado en el concejo de Madrid ${ }^{94}$. La viuda de uno de los hermanos, Diego García Mesurado, es también propietaria en 1452 y 1453 de ganado ${ }^{95}$ y tierras heredadas de los Mesurado ${ }^{96}$.

En los Carabancheles, el Alto y el Bajo, tenemos cuatro familias, los Zofio, los Aguado, los Rodajo y los García. Pedro García Zofio, Alonso García y María, la Zofia son los componentes de la primera, todos ellos

90 Efectivamente en 1466 Alonso, hijo de Juan Alonso, le demanda por haberle contratado como meseguero por quince fanegas de pan, trigo, cebada y centeno, más setenta maravedis y dos pares de zapatos y no haberle pagado parte de la soldada; AV, MINUTAS... III, f. 228v.

u1 En 1449 Juan García, hijo de García Fernández Vicente, debía al bachiller Pedro González de Madrid, y a su hermano, cuatro cahíces de pan, trigo y cebada, por media yunta de tierras en Torrejón de Aravaca; AV, MINUTAS... II, f. 172r.

92 En 1449 debía a Juan Sánchez de Soria y a Fernando de Aguilar, vecinos de Madrid, arrendadores de los menudos, queso y lana de Alcorcón, quinientos cincuenta y dos maravedís de diecinueve corderos y corderas que tuvo que diezmar; AV, MINUTAS... II, f. 174v.

93 De esta forma venden a Constanza de Ponte, mujer de Ruy Sánchez Zapata, vecina de Madrid, unas viñas jaén situadas en el sesmo de Villaverde; AV, MINUTAS... II, f. 119r y ss.

94 AV, MINUTAS..., II, f. 77r-v.

95 AV, MINUTAS... II, f. 252v.

${ }^{96}$ AV, MINUTAS... II, f. 299v. 
con propiedades inmuebles, viñas, casas y ganado, tanto ovino como bovino ${ }^{97}$.

Los Aguado con Miguel, Juan y Martín Aguado debieron disfrutar de cierta preponderancia local. En 1462 Miguel Aguado aparece como alguacil del concejo aldeano de Carabanchel Bajo ${ }^{98}$, mientras que Juan se encarga en 1464 de hacer el repartimiento de las pechas de Carabanchel Alto, interviniendo en distintos pleitos con vecinos del lugar por la cuantía de las mismas ${ }^{99}$. También en 1453 Martín aparece como sesmero de Aravaca ${ }^{100}$.

Los Rodajo, Benito Sánchez, su hijo Diego Martínez y Alonso Rodajo, son también una familia de campesinos con viñas en el lugar ${ }^{101}$, y algunas tierras arrendadas que les permiten obtener alguna ventaja fiscal en lo referente a determinadas prestaciones a las que los pecheros estaban obligados ${ }^{102}$. En 1449 Benito Sánchez Rodajo actuaba en nombre de la familia como administrador de los bienes de sus sobrinos menores de edad, vecinos de Carabanchel Alto, arrendando en su nombre algunas ovejas. Tienen también los Rodajo representación política en sus lugares, lo que demuestra su posición social. En 1462 Benito Sánchez figura entre los pecheros que forman parte del ayuntamiento aldeano de Carabanchel Bajo ${ }^{103}$, mientras que en el mismo año otro Rodajo aparece como alcalde de la aldea ${ }^{104}$.

Los García están representados por Nicolás García, vecino de Carabanchel Alto, quien arrienda junto a otros vecinos de su aldea, y de otros lugares del sesmo, como Pozuelo, la hierba de la dehesa de Cantarranas, probablemente para pasto de ovejas ${ }^{105}$. En 1463 se habla de los bienes de sus herederos, aún menores, cuando el padre muere, y que serían administrados por distintos tutores del lugar ${ }^{106}$, por lo menos hasta 1466 en

97 AV, MINUTAS... IV, f. $49 \mathrm{v}$.

AV, MINUTAS... II, f. 453v.

AV, MINUTAS... III, f. $110 \mathrm{~V}$.

100 AV, MINUTAS... II, f. 325r.

101 En 1466 Benito Sánchez Rodajo se quejaba ante el alcalde de Madrid porque teniendo un majuelo en Carabanchel Bajo halló ciertos daños en el mismo que suponía causados por vecinos de Carabanchel Alto, por ser lugar más cercano; AV, MINUTAS... III, f. $221 \mathrm{v}$.

102 Se trata del arrendamiento en 1464 por Benito Sánchez de media yunta de tierras de la heredad que Pedro Núñez tenía en Prado Longo. El contrato de una duración de seis años, estipulaba el franqueo de determinados servicios militares como velas, rondas, ballestería, lancería y guias; AV, MINUTAS... III, f. 193v.

103 AV, MINUTAS... II, f. 453v.

104 AV, MINUTAS... II, f. 453v.

105 AV, MINUTAS... II, f. 282r.

106 Es el caso de Pedro de Vallecas quien en 1463 aparece como su tutor recibiendo del anterior tutor, vecino de la aldea, cinco fanegas y media de centeno en cuenta del alcance que contra él tenía; AV, MINUTAS... III, f. 22v. 
que ya se menciona a un tal Alonso García, hijo de éste, arrendando unas tierras ${ }^{107}$. Se trata del mismo que algunos años más tarde, en 1473, aparece como alcalde de Carabanchel Alto ${ }^{108}$.

En Madrid y su sesmo hallamos a una representación de artesanos y mercaderes, junto a la oligarquía municipal como propietarios de ovejas y ganado. De entre los artesanos tenemos a un tejedor, Pedro Martín, relacionado por tanto con la industria textil, y al que en 1472 se le verificaban cuatrocientas ovejas. Junto al mismo el platero Garcia González también con reses ovinas.

Son los mercaderes quienes representan el mayor número de vecinos con rebaños de ovejas. La familia de la Puerta es ilustrativa en este sentido. Juan de la Puerta con quinientas reses en 1449, actuando en nombre de su hermano Pedro en la venta de carneros a los carniceros madrileños ${ }^{109}$, indica que en estos casos las ovejas se convertían en un valor mercantil más. Mención especial merecen los mercaderes judíos y mudéjares, casi siempre en relación al arrendamiento del diezmo del ganado, caso de Fraym Aben Xuxe y Menahen Çidre ${ }^{110}$, o al abastecimiento de las carnicerías. Independientemente de ello la inversión en ganado ovino era una fuente rentable de ingresos, tanto desde el punto de vista alimenticio (leche, carne, queso), como comercial (lana). Familias judías como los Çidre, Menahen, Abraham, o los Aben Xuxe, junto a los mudéjares Abdallá Toledano, Hazán o Hamet Merino ${ }^{111}$, son una muestra.

La oligarquía también está presente siguiendo el esquema de grandes propietarios. El regidor Pedro de Lusón, quien en 1449 aparece al mismo tiempo como tenedor del alcázar en nombre del rey ${ }^{112}$, o el también regidor Diego de Paredes. Junto a ellos el comendador Pedro Suárez y algunos caballeros como Andrés García de Hurosa o Pedro García de Villoslada. El sector de la nobleza estaría representado por personajes como don Alfonso Álvarez de Toledo para el reinado de Juan II, o Diego Arias Dávila, con Enrique IV.

107 AV, MINUTAS... III, f. 272r-v.

108 AV, MINUTAS... IV, f. $41 \mathrm{~V}-42 \mathrm{r}$

109 AV, MINUTAS... II, f. $63 \mathrm{r}$.

110 En 1449 Fraym Aben Xuxe de Toledo y Menahen Çidre tenían arrendada la renta de los corderos, queso y lana de Getafe, siendo Menahen el fiador; AV, MINUTAS... II, f. 58v.

111 Todos son propietarios de ovejas. Los Çidre aparecen como tales en 1453 y 1471 . Fraym Aben Xuxe en 1449. Los mudéjares como maestro Abdallá Toledano en 1472 con seiscientas ovejas, maestro Hazán en 1471 con corderos, o maestro Hamet Merino quien en 1464 era demandado por los carneros que habian entrado en una viña en el pavo de Vallecoso; AV, MINU. TAS... III, f. 151v.

112 AV, MINUTAS... II, f. 94V. 
Dejando la villa, y continuando con los sesmos de la tierra, pasamos al de Vallecas. Se trata de uno de los más extensos y poblados con aldeas como la propia Vallecas, Hortaleza, Fuencarral y Vicálvaro.

En Vallecas aparece algún modesto labrador como García Martín, quien solicita un préstamo de trigo al cura del lugar, lo que indica su posición económica ${ }^{113}$. Algunos años antes aparece como propietario de un rebaño de cien ovejas. Lo mismo sucede en Hortaleza con Pedro Martín con tan sólo treinta ovejas, y trabajando en 1471 la media yunta de tierras que tenía arrendadas en el lugar, lo que le permitía al mismo tiempo ser franqueado por su señor de algunos pechos reales, según el modelo de contrato concertado entre éste y el campesino ${ }^{114}$. En Vicálvaro poseemos algún dato sobre otro pequeño propietario, Juan Martín, también arrendatario y cuya viuda en 1472 tenía doscientas ovejas ${ }^{115}$.

En definitiva se trata en todos los casos de pequeños y medianos pecheros, todos propietarios de modestos rebaños y ninguno de bienes inmuebles, algunos debiendo recurrir al préstamo, sintoma de una posición económica no demasiado desahogada, y cuya única fórmula de acceder a la tierra era a través de contratos de arrendamiento de larga duración que les podian proporcionar algunos beneficios económicos y fiscales.

El sesmo de Villaverde con Villaverde, Getafe, Pinto y Leganés, constituye el ejemplo más paradigmático de la presencia de ovejas, así como de campesinos y ricos labradores que ejercen un papel preponderante en toda la estructura económica local.

En Villaverde hallamos a pequeños propietarios de ganado insertos en distintas actividades relacionadas con la ganadería, como es la compra de sal para los animales ${ }^{116}$. Algunos como Juan Sánchez, hijo de Alonso Martín, conseguian adquirir una cierta promoción social, integrándose en los resortes de la administración real, como monedero de la ceca de Cuenca, gozando de todos los privilegios y exenciones que se otorgaban a estos funcionarios regios ${ }^{117}$. Resulta evidente que, en este caso, fue la po-

113 AV, MINUTAS... $\|, f .248 \mathrm{v}$.

114 AV, MINUTAS... III, f. 347 r.

115 AV, MINUTAS... III, f. 346r.

116 De este modo en 1464 Antón Garcia, vecino de Villaverde, figura entre los vecinos del lugar reunidos en concejo para comprar treinta fanegas de sal para el ganado; AV, MINUTAS... III, f. $67 \mathrm{v}$.

117 En 1464 Juan Sánchez presentaba la carta de nombramiento como monedero ante el concejo de Madrid, cuyas autoridades mandaron dar traslado de la misma al procurador de los hombres buenos pecheros de Madrid y su tierra con el fin de que se tuviese en cuenta la exención fiscal del mismo; AV, MINUTAS... III, f. 126r-v. 
sición económica del mismo, como pechero mayor, lo que le permitió acceder a tal situación. Parece ser que algunos miembros de estas oligarquías rurales disponian de medios suficientes, gracias a su poder económico, para poder situarse en la cúspide de su grupo social.

Es en Getafe donde la existencia de esta oligarquía de labradores ricos se manifiesta con mayor claridad. Disponemos de abundante información sobre las principales familias del lugar, de forma que en algunos casos se puede seguir su rastro durante varias generaciones realizando diversas prosopografías.

Comenzaremos con la familia de los Pingarrones de la que tenemos noticias desde 1447 hasta el final del periodo que estudiamos. Aparecen como miembros más significativos de la misma, Juan Martín Pingarrón, Alonso Martínez Pingarrón, Pedro Fernández Pingarrón y Marina Alonso, la Pingarrona. Todos ellos son propietarios de tierras y ganado y consiguen cierta preeminencia a través de la política local. Juan Martín Pingarrón aparece como ganadero, realizando contratos de asociación de rebaños con pequeños propietarios ${ }^{118}$, y como dueño de carneros y ovejas en 1452 y 1466. También dispone de tierras, en este caso a través de su mujer ${ }^{119}$, así como de otros bienes inmuebles ${ }^{120}$. Al mismo tiempo forma parte del concejo aldeano, junto a otros miembros de su familia y como tal interviene de forma activa en toda la política local ${ }^{121}$. Lo mismo podriamos señalar de Pedro Fernández y de Alonso Martínez Pingarrón. Este último llegó a ser alcalde de Getafe en $1470{ }^{122}$.

Junto a los Pingarrones, los Donayre se erigen como la familia más importante. Hallamos información sobre algunos de ellos, caso de Juan González Donayre, Alfonso González Donayre y sus hijos Diego y Nuño Donayre. Juan González fue mayordomo de don Alfonso Alvarez de Toledo en sus heredades de Getafє, y como tal aparece en los años 1448 y $1449{ }^{123}$. Durante algún tiempo le vemos en relación tanto con la hacienda eclesial como con la regia. Así durante varios años va a intervenir en el arriendo de los diezmos de algunas iglesias locales, lo que le hace partícipe de todo el proceso de producción local, beneficiándose de una parte

118 AV, MINUTAS... II, t. 209v.

it9 AV, MINUTAS... II, f. 438r.

120 AV, MINUTAS... III, f. $456 r$.

121 En 1452 aparece entre los hombres buenos pecheros de Getafe, ayuntados en concejo en la iglesia del lugar para designar carnicero; AV, MINUTAS... II, f. 287r. De nuevo en 1463 vuelve a aparecer como representante del concejo aldeano; AV, MINUTAS... III, f. $25 \mathrm{r}$.

122 AV, MINUTAS... III, f. 501r.

123 AV, MINUTAS... I, f. 388r. 
importante del mismo. En 1449 se le cita como arrendador de la tercera parte del menudo de maravedis de la iglesia de Getafe ${ }^{124}$. En el mismo año toma a renta el diezmo de los corderos de Valdemoro ${ }^{125}$, así como el de los panes pontificales pertenecientes a las adeganas del territorio de $\mathrm{Vi}$ llaverde, diezmo del que había sido arrendador ya durante los años 1447 y $1448{ }^{126}$. Esta actividad le hizo participar también en las haciendas de otras iglesias, como la de Polvoranca en $1452{ }^{127}$, o la de la parroquia madrileña de san Juan en $1466{ }^{128}$, cuyos feligreses tenían propiedades y ganado en territorio de Getafe. En 1472 arrienda el pan pontifical de un lugar de señorío como Parla ${ }^{129}$. Como arrendador lo es también de las alcabalas de la aldea en 1452, disponiendo de esta forma, no sólo de una parte de los excedentes de la producción agropecuaria, sino también del comercio, actividad en la que participa ${ }^{130}$. Su holgada situación económica le permite actuar como prestamista de algunos campesinos madrileños. Así desde 1449 hasta 1452 presta diversas cantidades de trigo a vecinos de Getafe, Fuenlabrada y Alcorcón ${ }^{131}$. Sus posesiones territoriales se basan fundamentalmente en el viñedo. Aparece comprando y vendiendo majuelos y viñas. En 1460 vendía dos aranzadas a un vecino de Leganés por mil trescientos cincuenta maravedís ${ }^{132}$, y en el mismo año compraba varias viñas de pequeño tamaño junto a otros viñedos de su propiedad ${ }^{133}$. Estas adquisiciones al por menor demuestran la intención de configurar una gran propiedad vitícola, a costa muchas veces de pequeños campesinos que debian vender sus tierras para sobrevivir.

Pero el poder de Juan González se basa en la ganadería como propietario de ovejas con rebaños de tipo medio que nunca superan las qui-

124 En 1449 el mercader Juan Díaz, vecino de Madrid, arrendador del menudo de maravedís de Getafe, le dio poder para cobrar la tercera parte de la renta de este año por cuanto arrendó la tercera parte de la misma; AV, MINUTAS... II, f, 132v.

125 AV, MINUTAS... II, f. 135r-v.

126 AV, MINUTAS... II, f. $57 \mathrm{~V}$.

127 AV, MINUTAS... II, f. 197r.

128 Fue arrendador de prácticamente toda la hacienda de la iglesia, incluídos los panes pontificales, el vino, los corderos, el queso y la lana; AV, MINUTAS... III, f. $288 \mathrm{r}$.

129 AV, MINUTAS... IV, f. 33v.

130 AV, MINUTAS... II, f. 263r.

131 En 1440 recibe de Miguel Gómez, vecino de Fuenlabrada, doce fanegas de trigo del préstamo que le presto; AV. MINUTAS... II, f. 74r. En el mismo año es Juan Sánchez Peloche, vecino de Getafe, quien le ha de dar diez fanegas de préstamo; AV, MINUTAS... II, f. 81r; y en 1452 presta otras diez fanegas de trigo a Pedro González Ballestero, vecino de Alcorcón; AV, MINUTAS... II, f. 231v.

132 AV, MINUTAS... II, f. 437v.

133 Se trata de una viña mollar en el camino de Pinto de una aranzada, más otra mollar en Carrapozuela de tres cuartas y un majuelo también en Carrapozuela de veduño alvillo con doscientas treinta vides; AV, MINUTAS... II, f. 438 r. 
nientas cabezas. Demandas de caloñas por las infracciones cometidas por sus animales ${ }^{134}$, y la compra de sal para los mismos, indican el peso que estas actividades tuvieron en el conjunto de su economía ${ }^{135}$. Su actividad política es muy prolifera, y es, sin duda, consecuencia de su posición social y económica en el concejo aldeano. Aparece presente en distintas sesiones del mismo, en 1452 y en $1463^{136}$, casi siempre defendiendo los intereses de su grupo. Sin embargo tal poder económico le permitió un grado de intervencionismo en todas las esferas locales, que acabó asumiendo la representación no sólo de su propia aldea ante las autoridades de Madrid ${ }^{137}$, sino de todo el sesmo. De esta forma aparece su nombramiento como sesmero de Villaverde en $1458{ }^{138}$. Desde esta posición Juan González Donayre estaba totaimente capacitado para defender, tanto ante las autoridades municipales como reales, los intereses económicos de su propia oligarquía, y los de todos aquellos pequeños y medianos propietarios con los que se relacionaba.

El resto de los Donayre tuvieron una actuación parecida a la del precedente. Alfonso González tenía arrendadas en 1466 las tierras pertenecientes al beneficio curado de Getafe, lo que demuestra también una importante relación con la iglesia local en la obtención de beneficios ${ }^{139}$. Su participación política se manifiesta en 1472 cuando actúa como representante de la aldea en un pleito con los paniaguados de santo Domingo el Real por cuestiones fiscales ${ }^{140}$. Sus hijos y herederos, Diego y Nuño, continúan la tradición familiar como arrendadores, en este caso de renta local, arrendando en 1463 la mojoneria del lugar ${ }^{141}$, y en 1473 la carnicería, gestión en la que participarian conjuntamente los dos hermanos ${ }^{142}$. Las

134 AV, MINUTAS... III, f. 249r.

135 En 1464 compra seis fanegas de sal; AV, MINUTAS... III, f. 67v. Así mismo en 1471 vende a un vecino del lugar una fanega y media; AV, MINUTAS... III, f. 349v; y en 1472 vende a Alonso Martinez Pingarrón, también propietario de ganado, seis fanegas de sal; AV, MINUTAS... III, f. 441r.

${ }_{136}$ En 1452 en el ayuntamiento que se hizo para coger carnicero; AV, MINUTAS... II, f. 287v; asi como en 1463 de nuevo; AV, MINUTAS... III, f. $25 \mathrm{r}$.

137 En este caso actúa en representación de la aldea en el pleito que los vecinos mantienen con la mujer del comendador Pedro Suárez, importante propietario de ganado, por la concesión que el concejo le habia hecho de un ejido en La Torrecilla, cerca del río, en el término de Getafe, por ser en perjuicio de Madrid y su tierra. En este caso se amenaza incluso con llevar la protesta ante el mismo rey; AV, MINUTAS... III, f. 60r-v.

138 AV, MINUTAS... II, f. 397r.

139. En 1466 debía al bachiller Diego Fernández de Soler, cura de Getafe, ciento cuarenta y dos fanegas de pan, trigo y cebada, y doce cargas de paja por renta de todas las tierras del beneficio curado que arrendó desde santa María de agosto hasta siete años; AV, MINUTAS... III, f. $288 \mathrm{r}-\mathrm{V}$.

140 AV, MINUTAS... III, f. 488r.

141 AV, MINUTAS... III, f. 16v.

142 AV, MINUTAS... IV, f. $2 v-3 r$. 
actividades rurales como la compra de sal ${ }^{143}$ para el ganado, o el alquiler de un lagar para la producción de sus viñedos ${ }^{144}$, demuestran una condición de agricultores y ganaderos acomodados, lo que les lleva en 1472 a invertir una parte de sus beneficios en algunos bienes inmuebles, como el alquiler de un mesón en Getafe ${ }^{145}$.

Los Ricote son otra familia representativa del lugar con Pedro Martín Ricote y los hermanos Benito Sánchez y Juan Sánchez Ricote. El primero es propietario de ganado ${ }^{146}$, y de algún viñedo de cuyo usufructo goza a medias con el propietario de la tierra ${ }^{147}$. Al igual que éste Benito y Juan tienen ganado ovino, ovejas y carneros ${ }^{148}$, asi como viñas y algunas tierras de sembradura arrendadas ${ }^{149}$.

Junto a todos estos hallamos a multitud de labradores, también propietarios de ganado, tal es el caso de Alonso García Crespo ${ }^{150}$, Miguel de Overa ${ }^{151}$, Juan de Merlo ${ }^{152}$ y Juan de Olías, incluyendo a algunas mujeres como María García, la Dorada, poseedora de un rebaño de ovejas ${ }^{153}$.

Otra familia fueron los Martínez de Arriba, cuyo representante Miguel Martínez de Arriba tenía a su cargo en 1464 la mayordomía de la iglesia de Getafe, y como tal se hacía cargo del cobro de los maravedís de los corderos, queso y lana pertenecientes al diezmo de dicha iglesia ${ }^{154}$. Los

143 AV, MINUTAS... III, f. 67r.

144 AV, MINUTAS... III, f. $362 \mathrm{~V}$.

145 AV, MINUTAS... III, f. $553 \mathrm{v}$.

146 En 1449 aparece comprando un novillo a Pedro Martín del Álamo, vecino de Getafe, por 650 maravedis; AV, MINUTAS... II, f. 103v. Así mismo en 1464 adquiere junto a Marcos, hijo de García Martínez, una fanega de sal por setenta y ocho maravedis; AV, MINUTAS... III, f. $67 \mathrm{r}$.

${ }_{147}$ Se trata de Alonso Fernández Izquierdo, vecino del lugar, quien se compromete a cavar y plantar a medias con éste un majuelo blanco y mollar en una tierra de una aranzada de superficie, durante cinco años; AV, MINUTAS... III, f. 149v

148 En 1458 Benito Sánchez Ricote debía pagar un carnero a un vecino de Leganés; AV, MINUTAS... II, f. 401r; y en 1466 Juan Sánchez Ricote debía a Juan Martín Pingarrón algunos maravedís de la renta de la leche y lana de treinta ovejas que le arrendó; AV, MINUTAS... III, f. 278r.

149 AV, MINUTAS... III, f. $31 \mathrm{r}$ y $55 \mathrm{v}$.

150 En 1463 debía a un tal Juan Roldán, cuatrocientos setenta maravedís por renta de todas sus viñas que arrendó con dos tinajas para vino; AV, MINUTAS... III, f. 14r. Así mismo en 1464 compraba cuatro fanegas de sal para el ganado; AV, MINUTAS... III, f. 67r.

151 En 1471 era demandado por unos vecinos de Getafe junto a Pedro Prieto porque sus ganados habian dañado sus panes; AV, MINUTAS... III, f. 333r.

152 Este compraba en 1464 dos fanegas de sal; AV, MINUTAS... III, f. 67r. En 1472 y 1473 aparece como propietario de ganado; AV, MINUTAS... IV, f. $45 \mathrm{v}$.

${ }_{153}$ En 1472 un vecino de Getafe afirmaba que había echado en guarda de María una oveja; AV, MINUTAS... III, f. $486 \mathrm{v}$.

${ }^{154}$ Concretamente son tres mil trescientos treinta y tres maravedis que el arrendador de los corderos, queso y lana de esta iglesia, Pedro Gonzalez Candí, debía pagar al mayordomo como parte del diezmo correspondiente a la iglesia; AV, MINUTAS... III, f. 173r. 
Martín Obrero, con Miguel a la cabeza, alcanzan así mismo cierta notoriedad política, pues el mismo aparece como alcalde del lugar en $1472{ }^{155}$. Por último los Gasco con Miguel Pérez Gasco y su hijo Juan Gasco representan también la línea de propietarios y al mismo tiempo arrendadores de tierras ${ }^{156}$.

En Leganés tenemos a los Valdecacho y a los Honguero. En cuanto a los primeros, Miguel Pérez Valdecacho es propietario de viñas y una tierra de cereal que tenía arrendada en $1464{ }^{157}$. Los Honguero son tan representativos del lugar como lo puedan ser los Pingarrones o los Donayre para Getafe. De los cuatro miembros de esta familia de los que nos ha llegado información, Alonso García, Benito Honguero, Antón Fernández, Juan Alonso e Inés, la Honguera, se destaca en todos ellos su condición de propietarios de viñedos, tierras y ganado ${ }^{158}$.

Concluyendo podemos afirmar la existencia en tierra de Madrid de un grupo de pecheros, campesinos y labradores, propietarios de modestos rebaños de ovejas. Este grupo social no es ni mucho menos homogéneo, pues hallamos notables diferencias entre las distintas familias, según se ha puesto de manifiesto en otros estudios sobre la sociedad rural bajomedieval ${ }^{159}$. Desde labradores enriquecidos con propiedades territoriales, viñedos, tierras de cereal ${ }^{160}$, casas y demás bienes muebles relacionados con la infraestructura agraria (corrales, silos, etc.), hasta pequeños y medianos campesinos, algunos con una buena situación económica y otros con dificultades para salir adelante. En la mayoría de los casos se observa que casi todos son propietarios de algunas viñas, mientras que no todos están en posesión de tierras de sembradura. En este último caso se podría hablar de un limitado mercado de la tierra, al que muchos campesinos consiguieron acceder a través de largos contratos de arrendamiento muy beneficiosos por las ventajas económicas y fiscales que, en algunos casos, proporcionaban. Sin embargo no debemos crear una falsa imagen de la

155 AV, MINUTAS... III, f. 433v.

156 AV, MINUTAS... II, f. 3r-V.

157 AV, MINUTAS... III, f. 129r.

158 Por ejemplo sabemos que Alonso Fernández Honguero tería en 1458 una viña de 1 aranzada; AV, MINUTAS... II, f. 401v; y que su hijo Anton Fernández vende en 1452 a un vecino del lugar una corraliza para ganado junto al camino real; AV, MINUTAS... II, f. $216 \mathrm{v}$. En 1472 Inés, la Honguera, demandaba caloñas a un vecino porque un par de bueyes habían entrado en un trigo que tenía sembrado en territorio de Zorita; AV, MINUTAS... III, f. 511v.

t59 Ver el capítulo de la obra de W. Rosener sobre la estratificación social de la población campesina; W. Rosener, Los Campesinos en la Edad Media, Barcelona, 1990, 207 y ss.

160 J. P. MOLENAT, “Exploitations Viticoles et Ceréalières dans les Campagnes Tolédanes aux xıvéme et xvéme siécles", L'Exploitation des Grands Domaines dans L'Espagne de l'Ancien Régime, París, 1985, 15-38. 
realidad. En muchos casos dichos contratos iban acompañados de distintas formas de préstamo en dinero o en especie por parte del señor, lo que podía repercutir en una cierta sujeción económica del campesino como ha sido señalado para otros ámbitos medievales ${ }^{161}$. En la mayoría de los casos los estratos más superiores de este campesinado acceden a cargos locales (alguacil, alcalde, sesmero), lo que les permite un mayor control, no sólo práctico sino también teórico de las actividades económicas.

Una cuestión importante que debemos tener en cuenta son los aspectos fiscales relacionados con la producción ganadera. En este sentido el cobro del diezmo puede resultar interesante a la hora de determinar quiénes eran los propietarios de ovejas, así como los lugares de producción. En lo referente al arrendamiento de este impuesto eclesial, no nos interesan tanto los arrendatarios como los que lo han de pagar. De todas formas no es de extrañar que muchos de estos arrendadores de la Iglesia aparezcan como propietarios de rebaños, pues tanto en el caso de los beneficios curados, que en la mayoría de los casos incluían ovejas, como en el diezmo se podía satisfacer el censo en especie. Lo mismo podríamos señalar del clero que se beneficiaba, en nombre de sus respectivas iglesias, de una parte de la producción de sus feligreses. Es el caso del clérigo Pedro Sánchez, quien en 1464 habia concertado con un vecino de Las Rozas la venta de los corderos de su diezmo de Canillas y Canillejas en cuantía de mil setecientos setenta maravedís ${ }^{162}$. Tenemos algunos ejemplos más de 1444 y de 1464 referidos al beneficio curado. En el primer caso el cura de san Andrés daba facultad a Sancho de Quelas, vecino de Madrid, para cobrar de los renteros y sus bienes los maravedís de su beneficio curado, así del vino pontifical y menudos de maravedís, como de los corderos, queso y lana de su iglesia ${ }^{163}$. En 1464 Diego Sánchez de Bivar, clérigo de Vallecas y su anejo, la iglesia de La Torre del Campo, designaba al escribano García Díaz como arrendador de todos los frutos de su beneficio, incluídos los corderos, queso y lana ${ }^{164}$.

161 Es el caso de Italia y los créditos que los propietarios adelantaban en forma de grano, dinero y alimentos a sus arrendatarios como es el caso de ia llamada "mezzadria"; R. C. MUELLER, "La Situación Económica de Italia en la Baja Edad Media", Europa 1400, eds. F. SEIBT y W. EBERHARD, Barcelona, 1992, 192.

162 En este caso el clérigo demandaba al comprador por haberse comprometido a adquirirle el ganado y después haberio comprado de otro; Viernes, 17 de agosto de 1464, AV, MINUTAS... III, f. $148 \mathrm{v}$.

163 Jueves, 17 de septiembre de 1444, AV, MINUTAS... I, f. 264r.

164 Este arrendamiento se hizo por siete mil quinientos maravedis, dejando la posibilidad al arrendador de beneficiarse de todo lo que obtuviese en dicha renta; Martes, 11 de septiembre de 1464, AC, MINUTAS... III, f. 155v. 
Se han conservado muy pocos datos sobre pago del diezmo en relación al ganado. Sin embargo los testimonios que tenemos coinciden en algunos casos con los que poseemos sobre propietarios de ovejas. Es el caso de un Mesurado, Alonso García, vecino de Alcorcón, quien en 1449 debía satisfacer a los arrendadores quinientos cincuenta y dos maravedís de diecinueve corderos que tuvo que diezmar a su iglesia ${ }^{165}$.

También el cobro del diezmo puede proporcionarnos datos sobre los lugares más frecuentes de producción ovina. En este caso parece ser que fue Getafe, en el sesmo de Villaverde, uno de los más importantes. En 1464 este concejo aldeano a través de su procurador pedía a los diezmeros de los corderos, queso y lana de ese año, que acudiesen de nuevo a cobrar el diezmo que algunos vecinos no habian querido pagar durante los tres días que permanecieron en el lugar. Los arrendadores emplazaron a estos vecinos a traer sus diezmos en breve tiempo hasta los corrales de san Millán en Madrid, ya que de otra forma deberían pagar una multa de cincuenta mil maravedís, cantidad $\in$ n que se valoró el montante de dicho diezmo ${ }^{166}$.

Junto a los que aparecen como propietarios de ovejas en el pago de caloñas o en la cuestión del diezmo, hallamos también en la documentación a pastores y carniceros. Los primeros en función de su mismo trabajo que se remuneraba en ocasiones con ovejas, y los segundos por la adquisición de estos animales para el abasto de carne.

\section{LOS PASTORES}

A la hora de estudiar la ganadería ovina conviene no sólo atender a los factores cuantitativos y de propiedad, sino también a todos aquellos derivados de la guarda y protección de los rebaños. En este sentido estudiaremos algunos contratos de pastoría que nos ayuden a conocer mejor a estos trabajadores ruraies, de los que en definitiva dependía el buen equilibrio entre actividades agrarias y ganaderas. De dichos contratos obtendremos datos sobre quiénes eran los pastores, su procedencia, y lo que es más importante, las características y condiciones en las que se desarrollaba su trabajo, duración del contrato, retribuciones, etc.

Tenemos información sobre pastores desde 1444 hasta 1473. Ofrecemos una relación de los mismos por años indicando, cuando sea posible, el propietario para quien trabajan, así como el lugar en que se les sitúa.

165 Domingo, 9 de noviembre de 1449, AV, MINUTAS... II, f. 174v.

166 Sábado, 16 de junio de 1464, AV, MINUTAS... III, f. $121 \mathrm{v}$. 
Pastores madrileños

\begin{tabular}{lllc}
\hline AÑO & SEÑOR & PASTOR & LUGAR \\
\hline 1444 & J. de Escobar & Fernando & Fuencarral \\
1444 & A. Mtn. Villaverde & Juan Martín & Zorita \\
1444 & - & Alonso & Alcorcón \\
1444 & A. Ruiz de Córdoba & J. García & Hortaleza \\
1444 & - & D. Fernández & Aravaca \\
1444 & J. Mtn. Pingarrón & Antón Martín & Getafe \\
1445 & J. García Zofio & Pedro & Carabanchel \\
1447 & J. de la Puerta & Domingo García & Madrid \\
1447 & Andrés Garcia & Alonso García & Madrid \\
1447 & P. de la Puerta & J. Fdez. Vallejo & Madrid \\
1447 & Diego de Paredes & Andrés Martín & Madrid \\
1448 & Ruy Gzez. Catalán & J. Esterón & Madrid \\
1449 & P. García Villoslada & B. Sánchez & Madrid \\
1449 & P. de Lusón & Juan Sánchez & Madrid \\
1449 & Prior de san Martín & P. de Pinto & Madrid \\
1449 & - & P. Martín & Carabanchel \\
1449 & - & García Fdez. & Rejas \\
1452 & M. Mtnez. del Pozo & Juán & Getafé \\
1453 & Menahen Çidre & M. Sánchez & Madrid \\
1463 & Juan Alonso & P. de Borox & Getafé \\
1471 & P. del Valle & A. Sánchez & Leganés \\
1472 & Juan Gasco & Andrés & Fuencarral \\
1472 & J. de Sotos Alvos & P. Peloche & Getafe \\
1472 & J. de Olías & P. Mtn. Moreno & Getafe \\
1472 & Pedro y Juan Palomino & Juan Zalacón & Leganés \\
1473 & Fernando de Torrejón & P. Mtnez. de Hita & Madrid \\
1473 & Pedro Gutiérrez & Martín de Ocaña & Madrid \\
1473 & & & Pozuelo \\
\hline
\end{tabular}

La diversidad de contratos no permite señalar unas mismas condiciones para todos los casos. Sin embargo se puede hablar de ciertas generalidades más o menos comunes a todos ellos.

Comenzaremos por el período de duración que solía ser de un año. En estos casos lo normal era que el contrato comenzase el día de san Juan, 24 de junio, y acabase la misma fecha del año siguiente ${ }^{167}$. Sin embargo la fórmula más usual que encontramos en Madrid es la que determinaba un contrato que se extendía desde el día de san Pedro, 29 de

167 Pastor Baños, “La Lana en Castilla y León...», 387. 
junio, hasta cumplir el año ${ }^{168}$. Se hacía coincidir, por tanto, con el comienzo del verano, cuando los rebaños trashumantes estaban en Madrid y los campos ofrecian la máxima alerta, en vísperas de la siega y la vendimia ante los posibles perjuicios que el ganado pudiese ocasionar en los cultivos ya crecidos. También es probable que se aprovechase una de las reuniones de la Mesta local, celebrada por san Juan, como circunstancia propicia. En la misma se acordarían los contratos con las personas interesadas, materializándose días después ante el escribano en un documento escrito. De esta forma dichos contratos se referían tanto al caso de los ganados estantes, como al de la cabaña trashumante que iniciaba la marcha durante el otoño. Las variantes que hemos hallado a este tiempo no son demasiado significativas. Por ejemplo contratos que estipulan una duración desde febrero a san Pedro ${ }^{169}$, o de julio también al mismo día ${ }^{170}$. Junto a ellos algunos contratos de seis meses como en $1473{ }^{17 t}$.

Las diferencias retributivas eran las que definían en último término los distintos contratos de pastoría. Así hallamos un tipo de soldada muy característica que es la que se pagaba conjuntamente en dinero y en especie. Las cantidades en metálico variaban desde los cuarenta maravedís mensuales ${ }^{172}$, hasta los cien maravedís del contrato de 1449 entre el pastor Benito Sánchez y Pedro Garcia de Villoslada ${ }^{173}$. Entre los dos importes citados se encuentran cantidades intermedias como los sesenta maravedís al mes que en 1451 Menahen Çidre tuvo que pagar a Marcos Sánchez de Villacastín durante los casi cinco meses que estuvo a su servicio, lo que suponía un sueldo final de unos trescientos maravedís ${ }^{174}$. También en

168 Así aparece en dos contratos de 1447. Uno de junio de este año en el que Juan Fernández Vallejo, vecino de Porquerizas, entra por pastor de Pedro de la Puerta, vecino de Madrid; Jueves, 29 de junio de 1447; AV, MINUTAS... I, f. 338r. El otro es del mes de julio cuando Domingo García y Alonso García, vecinos de Vallecas, entran por pastores de Juan de la Puerta y Andrés García, vecinos de la villa, "para guardar su ganado ovejuno fasta quinientas ovejas que le tienen echadas a guardar e todo el otro ganado que le echaren desde san Pedro fasta un anno..."; Martes, 25 de julio de 1447; AV, MINUTAS... I, f. 352v. Tenemos también un ejemplo de 1473 en que Pedro Gutiérrez, vecino de Pozuelo, demanda a Martín de Ocaña, vecino del lugar, al que contrató por su pastor desde san Pedro del año anterior; Lunes, 6 de septiembre de 1473; AV, MINUTAS... IV, f. $23 \mathrm{v}$.

169 Se trata del contrato de febrero de 1452 entre Marcos Sánchez de Villacastin, vecino de Canillas, como pastor, y Menahen Çidre; Viernes, 9 de febrero de 1452; AV, MINUTAS... II, f. $328 \mathrm{v}$

170 Es la fórmula que aparece en el contrato de Juan, hijo de Juan Sánchez de Fuente el Saz. con Pedro de Lusón; Viernes, 4 de julio de 1449; AV, MINUTAS... II, f. 91r.

${ }_{171}$ Es el caso de Pedro Martínez de Hita cuando entra por pastor de Fernando de Torrejón, desde finales del mes de agosto hasta carnestollendas, por el mes de febrero; Jueves, 26 de agosto de 1473; AV, MINUTAS... IV, f. 10r-v.

172 Se trata del contrato por un año en julio de 1447, entre Domingo Garcia y Alonso Garcia, vecinos de Vallecas, y Juan de la Puerta y Andrés Garcia; AV, MINUTAS... I, f. $352 v$.

173 Sábado, 8 de febrero de 1449; AV, MINUTAS... II, f. 20r-V.

174 AV, MINUTAS... II, f. 328v. 
1473 se pagaban cuatrocientos maravedís anuales, exentos de diezmo, a razón de unos sesenta y seis maravedís y medio mensuales por otro contrato de seis meses ${ }^{175}$. En todo caso estas cifras suponen un nivel salarial de tipo medio que debemos poner en relación con factores como la duración del contrato o el número de ovejas a guardar. Por lo general lo contratos de un año podían estar mejor retribuidos, mientras que los de seis meses para abajo suponían la mitad o menos de la cantidad establecida en los anuales. Las diferencias salariales estribaban no sólo en el tamaño de los rebaños sino en otra serie de condiciones, algunas referentes a los pagos en especie.

Para Castilla se ha apuntado la costumbre de que los pastores participasen de una sexta parte de las ovejas que tenían a su cargo, así como de un quinto de la lana y quesos que obtenían de dichos rebaños ${ }^{176}$. Constituyen estos porcentajes los pagos en especie que en algunos contratos se alternaban con la entrega de dinero. En Madrid tal porcentaje se estableció en un séptimo, tanto para los corderos y corderas nacidos durante el año, como para el queso y la lana. Así aparece en los contratos de $1447^{177}$ y $1449^{178}$. Ello supone que los pastores podían convertirse en pequeños propietarios, pudiendo acceder al mercado de ganado o vender una parte de la soldada obtenida como el queso y la lana. Prueba de ello es que debian diezmar a sus correspondientes iglesias por los beneficios obtenidos. En 1449 Benito Sánchez, pastor de Pedro García de Villoslada debía satisfacer cinco maravedís y tres corderos y medio de los treinta que habia ganado de soldada ${ }^{179}$, y en 1463 el alcalde condenaba a Pedro de Borox, vecino de Getafe, a que pagase al arrendador de los corderos, queso y lana de la iglesia local, ciento treinta maravedís del diezmo de lo que ganó por guardar ganado ${ }^{180}$. En ocasiones se establecían exenciones de diezmo, que es de suponer pagaba el propietario del ganado, y que en la documentación se menciona con la expresión «estar forro de diesmo" "181. En todo caso se puede decir que las retribuciones en especie eran siempre preferibles, puesto que suponían la inserción del campesino en un comercio importante y fuertemente desarrollado con sus consiguientes beneficios, a una paga fija y única que en ocasiones no resultaba

175 AV, MINUTAS... IV, f. $10 \mathrm{r}-\mathrm{v}$.

176 PAStor Baños, "La Lana en Castilla y León...", 387.

177 De esta forma se dice que les han de dar a los pastores de siete corderos y corderas, uno, de siete quesos, uno, y de siete vellocinos de lana de lo basto, uno; AV, MINUTAS... I, f. 352v.

178 AV, MINUTAS... II, f. $91 \mathrm{r}$.

179 AV, MINUTAS... II, f. 20r-V.

180 Miércoles, 25 de mayo de 1463; AV, MINUTAS... III, f. 27r.

181 Lunes, 17 de julio de 1447; AV, MINUTAS... I, f. 343r. 
sensible a las posibles fluctuaciones de la economía en materia de precios y salarios.

Junto al propio ganado y los productos que ofrecía, algunos contratos estipulaban la entrega al pastor del atuendo para su trabajo, o bien el dinero para comprarlo. En el caso de la ropa se trataba del vestido o de la pieza de paño necesaria para confeccionarlo. En este sentido la documentación hace referencia al sayo como prenda habitual de los pastores. Tenemos varios ejemplos de ello en los que siempre se acuerda la entrega de doce varas de sayal, cantidad que debía considerarse suficiente para al menos tres o cuatro sayos ${ }^{182}$. Sólo en un contrato de 1447 referido a la guarda de ganado vacuno el pastor recibe una saya de paño de Buriel y un camisón ${ }^{183}$.

En cuanto al calzado se menciona el dinero que se daba para comprarlo, cantidad que se sitúa entre los cincuenta y sesenta maravedís ${ }^{184}$, siendo esta última cifra la más frecuente. Como en la ropa también aparecen menciones a zapatos, suelas y zapatas ${ }^{185}$. Es interesante observar que la entrega del calzado aparece supeditada a la duración del contrato. De esta forma las cantidades arriba reseñadas hacen referencia a contratos anuales, mientras que para los de menor duración se utilizan expresiones tan vagas como "el que oviere menester" ${ }^{186}$, o se especifica la mitad de dichas cantidades ${ }^{187}$. Es evidente que se establecía una relación lógica entre el tiempo que el pastor debía estar cuidando el rebaño y el desgaste que por ello podía sufrir el calzado. En cualquier caso hemos comprobado que en contratos de unos seis meses de duración se estipula la entrega de entre dos y tres pares de zapatos.

Con todo ello no es difícil imaginar la estampa del pastor medieval madrileño. A este propósito hemos conservado una importante descripción referente a un pastor de Pedro Díaz, vecino de Madrid, y a su ayudante, cuando estaban guardando ovejas junto al camino de santa María de Atocha en un mes de julio de 1473. Así lo describe el documento:

82 AV, MINUTAS... I, f. 338r.

183 AV, MINUTAS... I, f. 343r.

184 AV, MINUTAS... I, f. 338r.

185 En 1453 Marcos Sánchez de Villacastín recibió de Menahen Çidre por guardarle su ganado ovejuno y cabruno dos pares de zapatas y suelas; AV, MINUTAS... II, f. 328v. También en 1473 Pedro Martínez de Hita ganaba como soldada tres pares de zapatas para su calzar, cada vez que las necesitase; AV, MINUTAS... IV, f. 10r-v.

186 AV, MINUTAS... I, f. 343r.

187 Sábado, 24 de octubre de 1472; AV, MINUTAS... III, f. 534V-535r. 
"Que guardava el dicho ganado un ome que tenia un sayo pardillo desmangado e traya unas mangas pardillas, e que andava con el un moço pequenno crespo con un sayo de sayal blanco..." ${ }^{188}$.

Algunos contratos especifican la existencia junto al pastor de personal ayudante. Son los llamados rabadanes, por lo general niños y mozos de corta edad, de los que no se menciona salario alguno ${ }^{189}$. Se trataba de una mano de obra barata y que podía llegar a ser de un gran rendimiento. En ocasiones se mencionan las tareas para las que se les utilizaba, como en el tiempo en que las ovejas parían, o cuando había que ordeñarlas. En estos casos un contrato de 1447 señala no a niños, sino a jornaleros contratados exclusivamente para ello ${ }^{190}$. También era frecuente que el mismo pastor solicitase "ayudador", no responsabilizándose del daño que el ganado pudiese producir si el propietario no accedía, sobre todo en el caso de grandes rebaños difíciles de controlar ${ }^{191}$.

Independientemente del salario en dinero y especie el propietario, como en cualquier contrato de servicio, se hacía cargo tarnbién de la manutención, comida y bebida. Referente a esto hemos observado una cierta estratificación alimenticia, en expresiones tales como, "segund que a ellos conviniere..." ${ }^{192}$, lo que nos permite hablar de una serie de hábitos gastronómicos, que en el caso de los pastores se basaban en el pan, el vino, la carne y el queso ${ }^{193}$. A cambio de la manutención los pastores debian responder personalmente del ganado encomendado dando cuenta con su pago correspondiente al propietario. Estos pagos podian hacerse en dinero o en especie, siendo frecuente la concesión de préstamos por el mismo propietario en el momento de realizarse el contrato, dinero que al pastor debía devolver al finalizar su trabajo ${ }^{194}$. Igualmente el pastor se comprometía, en expresión de la época, a “abrebar e apaçentar el ganado...» ${ }^{195}$,

188 Lunes, 16 de agosto de 1473; AV, MINUTAS... IV, f. $3 v$.

189 AV, MINUTAS... III, f. 534v-535r.

190 AV, MINUTAS... I, f. 352v.

191 Así Andrés, hijo de Juan de Torrejón, entraba como pastor de Pedro del Valle, vecino de Fuencarral, para que guardase el ganado de su madre, siendo necesario que le diese también un ayudador, sin lo cual el pastor no sería responsable de los daños que hiciese el ganado, siendo el propio Pedro del Valle quien correría a cargo de los mismos; Lunes, 20 de abril de 1472; AV, MINUTAS... III, f. 444r.

i92 AV, MINUTAS... I, f. 352v.

${ }_{193}$ En el privilegio que Sancho IV concede a los ganados de santo Domingo el Real de Madrid para que gozase de exenciones fiscales en todo el Reino, se señala que los pastores podían, entre otras cosas, cortar leña para cocer su pan y hacer espetas para asar su carne, así como entremiso con sus pies para hacer queso y queseras para guardarlo; Carta dada en Valladolid a 26 de noviembre de 1284; AHN., Clero, carp., 1356, $n^{\circ} 10$

194 Lunes, 17 de julio de 1447; AV, MINUTAS... I, f. 344r.

195 AV, MINUTAS... I, f. 338r. 
siendo también responsable del pago de las caloñas, excepto cuando no pudiese pagarlas, en cuyo caso sería el señor quien lo haría, según se recoge en las mismas ordenanzas municipales de $1380{ }^{196}$.

Cuadro de retribuciones de los pastores madrileños

\begin{tabular}{cccc}
\hline METÁLICO & ESPECIE & ATUENDO & ALIMENTOS \\
\hline $100 \mathrm{mrs}$. & 30 corderos & - & comida y bebida \\
$60 \mathrm{mrs}$. & - & zapatos & $\begin{array}{l}\text { comida y bebida } \\
\text { comida y bebida }\end{array}$ \\
$40 \mathrm{mrs}$. & $1 / 7$ especie & varas de sayal & com \\
\hline
\end{tabular}

En resumen podemos concluir señalando que la ganadería lanar madrileña tuvo su importancia en la Edad Media como parte de unas estructuras económicas que la convertían en el punto de referencia de otras actividades relacionadas con la alimentación y la industria del vestido. Los rebaños de ovejas, carneros y corderos con sus pastores y rabadanes pululaban por cañadas y caminos entre viñedos y sembrados. La estampa que ofrecía la villa y sus alrededores durante todo el año con los pequeños rebaños, y especialmente en los meses de primavera y verano durante la veranada con los rebaños más grandes que participaban en la trashumancia, debía ser bien significativa del papel que el ganado ovino desempeñaba en la economía local. Igualmente el paso de los grandes rebaños mesteños por el término madrileño siguiendo el trazado de las cañadas reales significaba la inserción de Madrid en unas estructuras ganaderas sociales, económicas y fiscales manifestadas en una estrecha relación de convivencia con la Mesta que no siempre fue pacífica y que demuestra de forma clara el alto grado de proteccionismo local de los concejos castellanos frente a las grandes intereses señoriales e institucionales.

Otro aspecto es la fuerte implicación de la mayoría de los madrileños tanto de la villa como de la tierra en todas las actividades derivadas de esta ganadería, artesanos, mercaderes, campesinos ricos y pobres, eclesiásticos, caballeros y nobles, judíos, mudéjares y cristianos, todos ellos muestran interés por tener ovejas y participar en una parte importante de

196 «Que las calonnas sean tenudos de lo pagar los sennores del ganado por que los dichos sennores dan sus soldadas e sus annahagas a los pastores e vaqueriços e yugueriços e porqueriços e a los otros que guardan los ganados y ordenan que los que ovieren de aver las calonnas que lo demanden a los dichos pastores e sy estos no tuvieren de que pagar que sean los sennores del ganado"; MiLlares, I, 160. 
la estructura económica local. Las ovejas son un valor económico más como sucede con casas, tierras y viñas, hasta tal punto que su posesión o tenencia se convierte en el mejor indicador para definir la existencia de una oligarquía rural fuerte social y económicamente y muy influyente en sus respectivos ámbitos aldeanos. Si Madrid fue tierra de pan y vino, lo es también de ovejas y ello ha condicionado parte de su toponimia y de las gentes de su ámbito rural.

En un Madrid sobreurbanizado con la mayor parte de las antiguas aldeas de su término desaparecidas o convertidas en ciudades dermitorio y sometidas a las complejas leyes de la especulación inmobiliaria, el recuerdo histórico a través de este modesto trabajo de lo que en un tiempo fueron campos y ovejas es el mejor homenaje a unas gentes y a un tiempo pasados pero no olvidados. 